\title{
Oxide Dispersion Strengthened Fe Al-Based Alloy Tubes: Application Specific Development for the Power Generation Industry
}

\author{
Research Sponsored by the U.S Department of Energy \\ Office of Fossil Energy \\ Advanced Research Materials Program
}

Report Prepared by

Bimal K. Kad

University of California-San Diego, La Jolla, CA 92093-0085

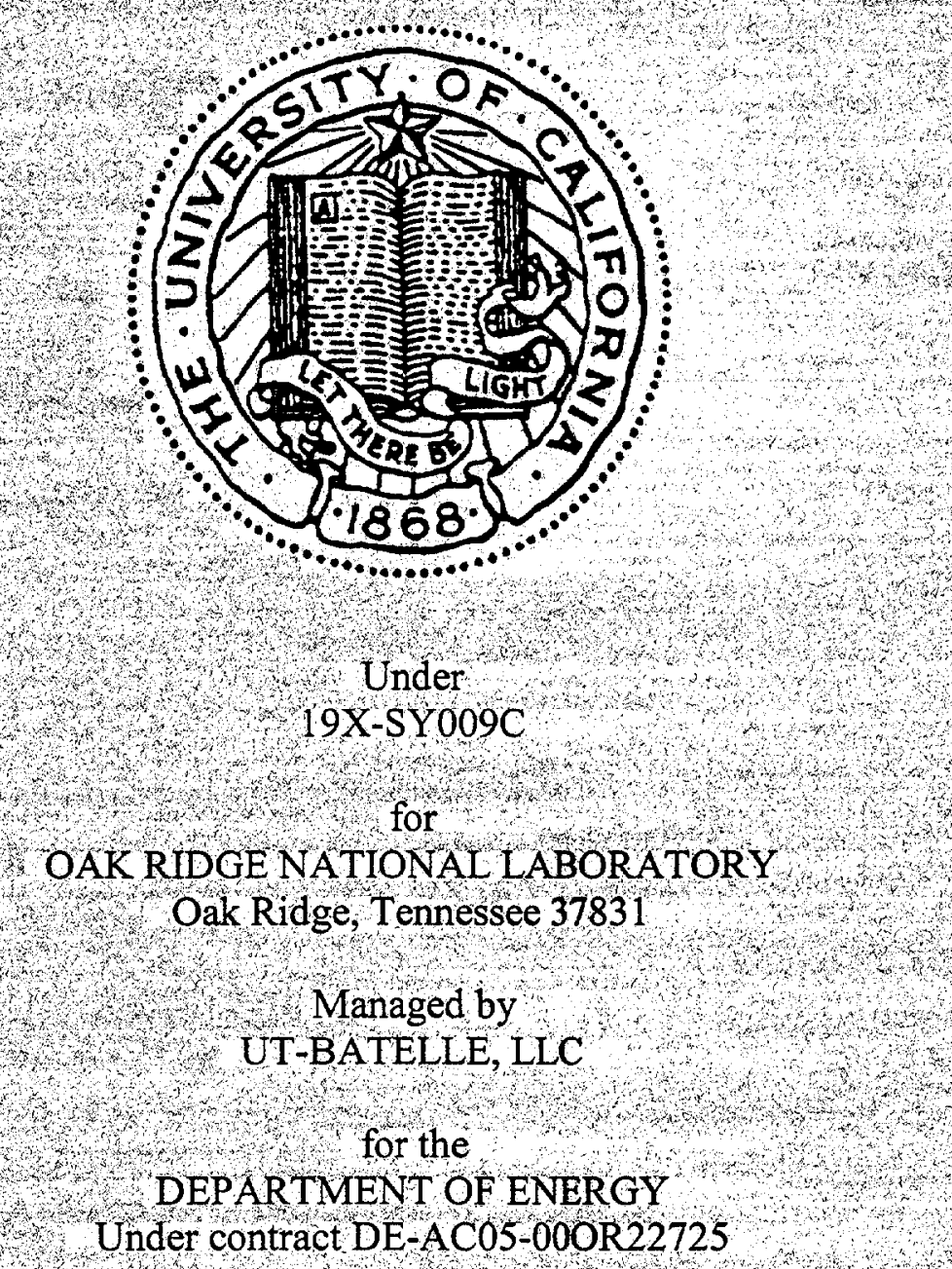

October 2001 


\title{
Oxide Dispersion Strengthened $\mathrm{Fe}_{3}$ Al-Based Alloy Tubes: Application Specific Development for the Power Generation Industry
}

\author{
Research Sponsored by the U.S. Department of Energy \\ Office of Fossil Energy \\ Advanced Research Materials Program
}

\section{Report Prepared by}

Bimal K. Kad

University of California-San Diego, La Jolla, CA 92093-0085

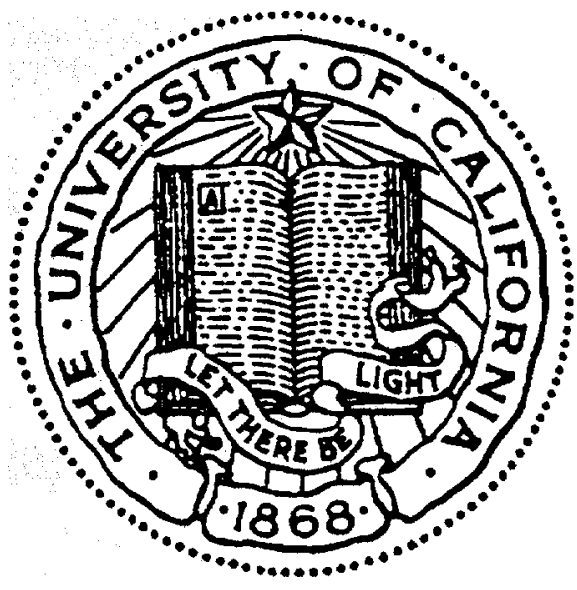

Under

19X-SY009C

for
OAK RIDGE NATIONAL LABORATORY
Oak Ridge, Tennessee 37831
Managed by
UT-BATELLE, LLC
for the
DEPARTMENT OF ENERGY
Under contract DE-AC05-00OR22725

October 2001 


\section{Oxide Dispersion Strengthened $\mathrm{Fe}_{3} \mathrm{Al}-\mathrm{Based}$ Alloy Tubes: Application Specific Development for the Power Generation Industry}

\section{Table of Contents}

$\begin{array}{ll}\text { Summary } & 1\end{array}$

$\begin{array}{lr}\text { Introduction } & \mathbf{2}\end{array}$

$\begin{array}{lr}\text { Program Particulars } & 2\end{array}$

Progress: Iteration 1 - rod extrusions 4

As-extruded Mechanical Anisotropy 5

As-extruded Texture Anisotropy 5

$\begin{array}{ll}\text { Recrystallization Kinetics } & \mathbf{6}\end{array}$

Recrystallization Kinetics with Pre-strain $\quad 7$

Progress: Iteration 2 - rod extrusions 9

As-extruded Texture Anisotropy 9

Recrystallization Kinetics 9

Progress: Iteration 3 - tube extrusions 12

Hardness Properties \& Recrystallization Kinetics 14

Recrystallized Grain Shapes \& Morphologies $\quad \mathbf{1 5}$

Progress: Iteration 4-Tube extrusions $\quad 20$

TEM microstructures $\quad \mathbf{2 0}$

Precipitate Chemical Analyses $\quad 21$

Progress: Iteration 5 - Tube extrusions $\quad 20$

High Temperature Mechanical Response $\quad 23$

Progress: Iteration 6 - Tube extrusions 27

High Temperature Creep Response $\quad \mathbf{2 7}$

Creep Deformation Response Microstructures 29

$\begin{array}{ll}\text { Summary } \& \text { Conclusions } & 3\end{array}$

A cknow l e d g e m e n t s

$\begin{array}{ll}\text { References } & 33\end{array}$

$\begin{array}{ll}\text { Appendix } & 34\end{array}$ 


\title{
Oxide Dispersion Strengthened FezAl-Based Alloy Tubes: Application Specific Development for the Power Generation Industry
}

\begin{abstract}
Summary
A detailed and comprehensive research and development methodology is being prescribed to produce Oxide Dispersion Strengthened (ODS)-Fes $\mathrm{Al}$ thin walled tubes, using powder extrusion methodologies, for eventual use at operating temperatures of up to $1100 \%$ in the power generation industry. A particular 'in service application' anomaly of FesAl-based alloys is that the environmental resistance is maintained up to $1200^{\circ} \mathrm{C}$, well beyond where such alloys retain sufficient mechanical strength. Grain boundary creep processes at such high temperatures are anticipated to be the dominant failure mechanism.
\end{abstract}

Thus, the challenges of this program are manifold: 1$)$ to produce thin walled ODS-Fe $3 \mathrm{Al}$ tubes, employing powder extrusion methodologies, with 2) adequate increased strength for service at operating temperatures, and 3) to mitigate creep failures by enhancing the as-processed grain size in ODS-Fes $\mathrm{Al}$ tubes.

Our research progress till date has resulted in the successful batch production of typically 8 Ft. lengths of 1-3/8" diameter, 1/8" wall thickness, ODS-Fe 3 Al tubes via a proprietary single step extrusion consolidation process. The process parameters for such consolidation methodologies have been prescribed and evaluated as being routinely reproducible. Such processing parameters (i.e., extrusion ratios, temperature, can design etc.) were particularly guided by the need to effect post-extrusion recrystallization and grain growth at a sufficiently low temperature, while still meeting the creep requirement at service temperatures. Static recrystallization studies show that elongated grains (with their long axis parallel to the extrusion axis), typically $200-2000 \mu \mathrm{m}$ in diameter, and several millimeters long can be obtained routinely, at $1200^{\circ} \mathrm{C}$. The growth kinetics are affected by the interstitial impurity content in the powder batches. For example complete recrystallization, across the tube wall thickness, is observed for clean powders (PMWY-3) and consequently this powder batch exhibits the best creep performance. Prolonged exposures (about 700 hours) at $10 \mathrm{Ksi}$ at $1000^{\circ} \mathrm{C}$ have been achieved till date. The high impurity content powder batches (PMWY-1 and PMWY-2) exhibit modest improvements in tensile and creep response behavior at $1000^{\circ} \mathrm{C}$ upon further selective heat-treatments intended to increase grain size.

Research sponsored by the US Department of Energy, Fossil Energy Advanced Research and Technology Development Program, DOE/FE AA 151010 0, Work Breakdown Structure Element UCSD-2. 


\section{Introduction}

$\mathrm{Fe}_{3} \mathrm{Al}$-based alloys are promising materials for high temperature, high pressure, tubing applications, due to their superior corrosion resistance in oxidizing, oxidizing/ sulphidizing, sulphidizing, and oxidizing/chlorinating environments. Such high temperature corroding environments are nominally present in the coal or gas fired boilers and turbines in use in the power generation industry. Currently, hot or warm working of as-cast ingots by rolling, forging or extrusion in the $650-1150^{\circ} \mathrm{C}$ temperature range is being pursued to produce rod, wire, sheet and tube products [1,2]. A particular 'in service application' anomaly of $\mathrm{Fe}_{3} \mathrm{Al}$-based alloys is that the environmental resistance is maintained up to $1200^{\circ} \mathrm{C}$, "well beyond where such alloys retain sufficient mechanical strength. Thus, powder metallurgy routes, incorporating oxide dispersions (ODS), are required to provide adequate strength at the higher service temperatures.

The target applications for ODS-Fe 3 Al base alloys, in the power generation industry, are thin walled ( 0.1 " thick) tubes, about 1 to 3 inches in diameter, intended to sustain internal pressures (P) of up to $1000 \mathrm{psi}$ at service temperatures of $1000-1200^{\circ} \mathrm{C}$. The economic incentive is the low cost of $\mathrm{Fe}_{3} \mathrm{Al}$-based alloys and its superior sulphidization resistance, in comparison to the competing Fe-Cr-Al base alloys and the Ni-base superalloys currently in service.

\section{Program Particulars}

In December 1997, the University of California-San Diego (UCSD) was awarded a research subcontract to engage in a detailed and comprehensive research and development effort to produce thin walled ODS-Fe 3 Al tubes, using powder extrusion methodologies, for eventual use at operating temperatures of up to $1100^{\circ} \mathrm{C}$ in the power generation industry. Grain boundary dominated creep processes at such high service temperatures are anticipated to be the dominant failure mechanism.

Within the framework of this intended target application!,' the development of suitable materials containing $\mathrm{Y}_{2} \mathrm{O}_{3}$ oxide dispersoids, must strive to deliver both a combination of high mechanical strength at temperature, as well as prolonged creep-life in service. Such design requirements are often at odds with each other, as strengthening measures severely limit the asprocessed grain size, detrimental to creep life. Thus post-deformation recrystallization, or zone annealing, processes are necessary to increase the grain size, and possibly modify the grain shape for the anticipated use.

II

In this current project we address manufacturing issues and development efforts towards our stated development goal. The challenges of this program are "many-fold: 1) to produce thin walled ODS-Fe ${ }_{3} \mathrm{Al}$ tubes, employing powder extrusion methodologies, with 2) adequate increased strength for service at operating temperatures, and 3) to mitigate creep failures by enhancing the as-processed grain size in ODS-Fe $3 \mathrm{Al}$ tubes. The detailed task structure is shown in Figure 1. The project is iterative in nature, intended to systematically examine the various subprocesses for optimum performance and cost considerations. This entails i) prescription of material compositions and consolidation methodologies (single vis. multiple step) to create tubes, ii) prescribing zone annealing and recrystallization schedules to create large grain sized creep resistant tubes, and iii) direct verification of improved high temperature response. 


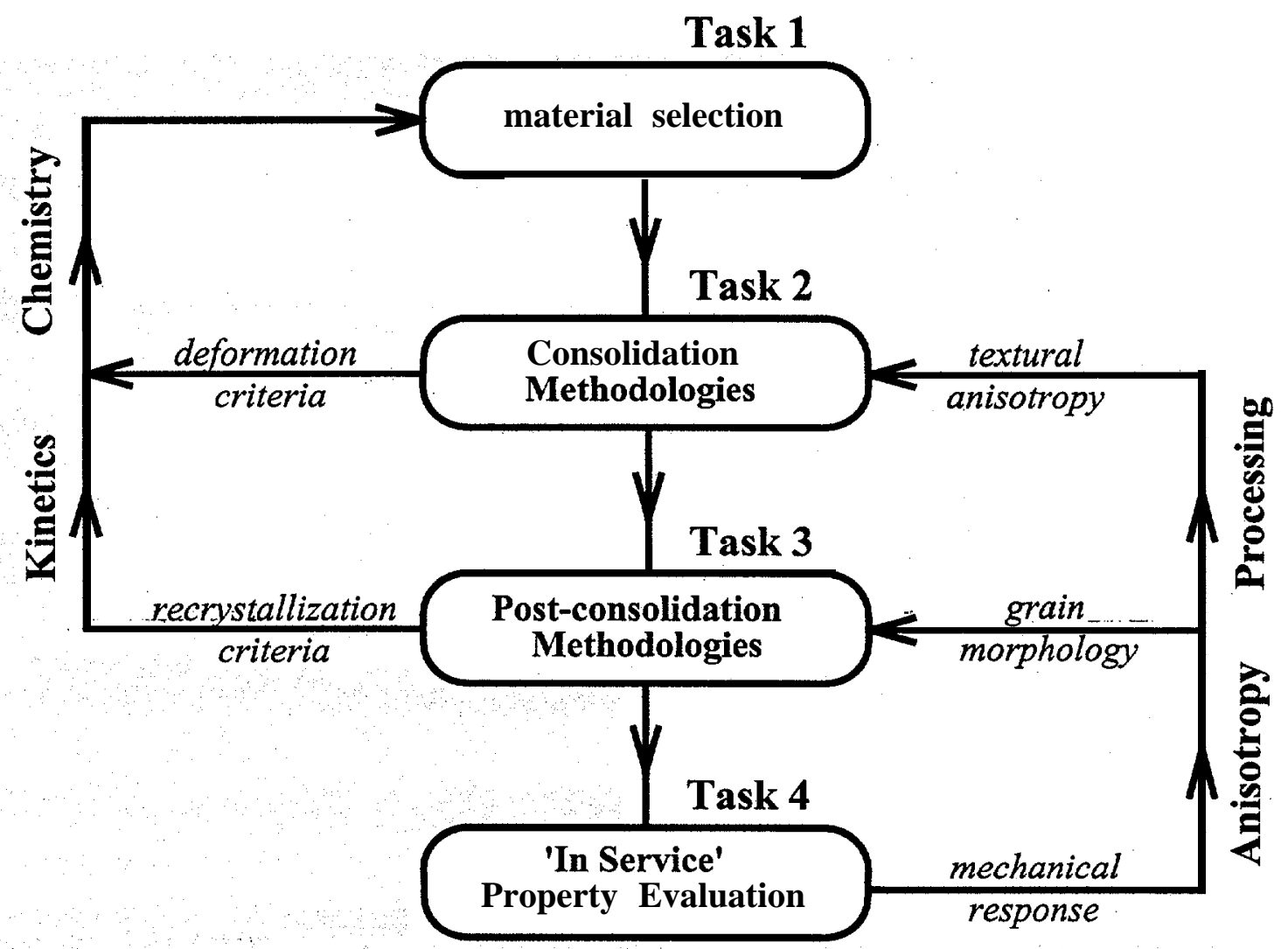

Figure 1. Schematic of the iterative research and development methodology for ODS$\mathrm{Fe}_{3} \mathrm{Al}$ based alloy tubes.

\section{Progress Status and Report}

This report describes the processing, microstructure and properties of ODS-Fe ${ }_{3} \mathrm{Al}$ alloy tubes, with a view to improving the high temperature creep response. Our work has focused on all Tasks l-4 illustrated in Figure 1, and our progress in these tasked areas is outlined below; in iterative sequence. The progress reported here has been previously described in Quarterly Management Reports, and in the $12^{\text {th }} .13^{\text {th }}, 14^{\text {th }}$ and $15^{\text {th }}$ Fossil Energy Conference Reports [6,7].

Our research has resulted in the successful batch production of typically $8 \mathrm{Ft}$. lengths of 1$3 / 8$ " diameter, $1 / 8$ " thick ODS-Fe $3 \mathrm{Al}$ tubes via a proprietary single step extrusion consolidation process. The process parameters for such consolidation methodologies have been prescribed and evaluated as being routinely reproducible. Such processing parameters (i.e., extrusion ratios, temperature, can design etc.) are particularly guided by the need to effect post-extrusion recrystallization and grain growth at a sufficiently low temperature, while still meeting the creep requirement at service temperatures. Static recrystallization studies show that elongated grains (with their long axis parallel to the extrusion axis), typically $200-2000 \mu \mathrm{m}$ in diameter, and several millimeters long can be obtained routinely in selected compositions; at $1200^{\circ} \mathrm{C}$. However, such grain growth does not necessarily span the entire wall thickness. The recrystallized region is most commonly bounded by unrecrystallized rings at the outer an inner periphery of the tube thickness, their relative dimensions dictated by the specific level of impurity. The ensuing creep response varies with the overall grain structure. 


\section{Progress: Iteration 1}

The $\mathrm{Fe}_{3} \mathrm{Al}+0.5 \% \mathrm{Y}_{2} \mathrm{O}_{3}$ composition mix was tentatively optimized at ORNL, and three separate batches were milled, identified as PMWY-1, PMWY-2 PMWY-3 in Table 1, details of which are available elsewhere [3]. PMWY-1 powder batch contained the maximum amount of interstitial impurities, and PMWY-3 the minimum. For the purposes of initial extrusion consolidation, the intermediate level impurity powder PMWY-2 was employed.

Experimental efforts were undertaken to consolidate the ODS powder, to produce sound stock material to be used for materials characterization and preliminary recrystallization studies. In this first iteration powder consolidation extrusions were carried out in carbon steel cans.

Table 1: Chemical analyses of the as-received and milled powder batches

\begin{tabular}{|c|c|c|c|c|c|}
\hline \multirow{2}{*}{ Element } & \multicolumn{2}{|c|}{ As-Received } & \multirow{3}{*}{ PMWY-1 } & \multirow{2}{*}{ PMWY-2 } & \multirow{2}{*}{ PMWY-3 } \\
\hline & $\mathbf{H M}$ & PM & & & \\
\hline $\mathrm{Fe}$ & Bal. & 79.6 & & & \\
\hline $\mathrm{Al}$ & 16.3 & 18.20 & & & \\
\hline $\mathrm{Cr}$ & 2.4 & 2.18 & & & \\
\hline $\mathrm{Zr}$ & $20 \mathrm{ppm}$ & $26 \mathrm{ppm}$ & & & \\
\hline$O$ (total) & $60 \mathrm{ppm}$ & $110 \mathrm{ppm}$ & $1800 \mathrm{ppm}$ & $1900 \mathrm{ppm}$ & $1400 \mathrm{ppm}$ \\
\hline $\mathrm{O}\left(\right.$ in $\left.\mathrm{Y}_{2} \mathrm{O}_{3}\right)$ & & & $1025 \mathrm{ppm}$ & $1053 \mathrm{ppm}$ & $1080 \mathrm{ppm}$ \\
\hline O balance & & & $775 \mathrm{ppm}$ & $847 \mathrm{ppm}$ & $320 \mathrm{ppm}$ \\
\hline O pickup & & & $665 \mathrm{ppm}$ & $737 \mathrm{ppm}$ & $210 \mathrm{ppm}$ \\
\hline $\mathrm{N}$ & $18 \mathrm{ppm}$ & $7 \mathrm{ppm}$ & $1264 \mathrm{ppm}$ & $145 \mathrm{ppm}$ & $88 \mathrm{ppm}$ \\
\hline N pickup & & & $1257 \mathrm{ppm}$ & $138 \mathrm{ppm}$ & $81 \mathrm{ppm}$ \\
\hline $\mathrm{C}$ & & $24 \mathrm{ppm}$ & $667 \mathrm{ppm}$ & $360 \mathrm{ppm}$ & $303 \mathrm{ppm}$ \\
\hline C pickup & & & 643 ppm & $336 \mathrm{ppm}$ & 279 ppm \\
\hline$\overline{\mathrm{H}}$ & & $16 \mathrm{ppm}$ & $115 \mathrm{ppm}$ & $40 \mathrm{ppm}$ & $29 \mathrm{ppm}$ \\
\hline $\mathrm{C}+\mathrm{N}+\mathrm{O}$ pickup & & & $2565 \mathrm{ppm}$ & $1211 \mathrm{ppm}$ & $570 \mathrm{ppm}$ \\
\hline
\end{tabular}

(Bulk compositions are identified in wt\%)

The carbon steel cans were 51-mm OD x $6.4 \mathrm{~mm}$ wall x $125 \mathrm{~mm}$ length (2-in x 0.25-in x 5in). The cans were filled with powder, evacuated and sealed. A total of three cans were prepared for direct consolidation of powder into solid bars, the details of which are provided in Table 2.

Table 2: Extrusion consolidation parameters for PMWY-2 powders

\begin{tabular}{||c|c|c|c|c|c||}
\hline \hline \multicolumn{2}{|c|}{ F.xtrnionn } & \multicolumn{2}{c||}{ Die Size } & Area & \\
\hline Number & Temperature & $\mathrm{mm}$ & inch & Reduction & Tonnage \\
\hline $\mathbf{5 0 1 6 ^ { \mathrm { a } }}$ & 900 & 16.3 & 0.64 & $9.8: 1$ & 266 \\
\hline $5014^{\mathrm{a}}$ & 1000 & 12.7 & 0.50 & $16.0: 1$ & 290 \\
\hline $5013^{\mathrm{a}}$ & 1100 & 12.7 & 0.50 & $16.0: 1$ & 180 \\
\hline $5030^{\mathrm{b}}$ & 1000 & 25.4 & 1.00 & $12.25: 1$ & 532 \\
\hline
\end{tabular}

a $5 \mathrm{lmm}$ (2.0 in) billets for solid extrusion; b82 $\mathrm{mm}$ ( $3.5 \mathrm{in})$ billet for tube extrusion. 


\section{$\underline{\text { As-extruded Mechanical Anisotropy }}$}

Knoop hardness measurements were made on longitudinal sections of extruded rods, in directions parallel $\left(0^{\circ}\right.$ degrees $)$, inclined $\left(45^{\circ}\right.$ degrees $)$ and perpendicular $\left(90^{\circ}\right.$ degrees $)$ to the elongated grains. Figure 2 shows the hardness response of the three extrusions, where the data scatter represents variations along the radial dimension of the extrusions. Both the 0" and 90" hardness measurements follow the expected decline with increasing extrusion temperature. The $45^{\circ}$ indents show anomalous behavior with temperature. Nonetheless, the strength anisotropy was relatively small (about $\mathbf{5 \%}$ ), and the material was deemed mechanically isotropic.

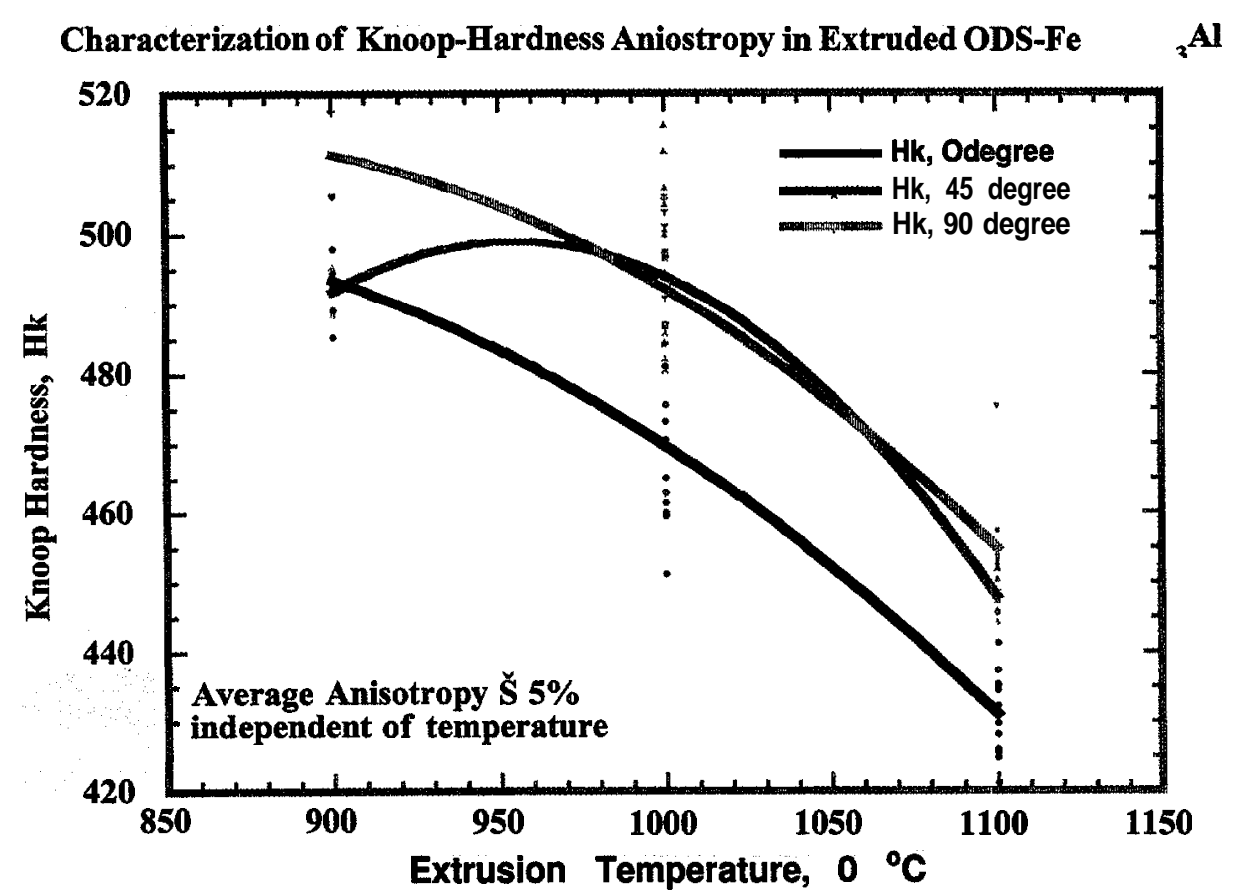

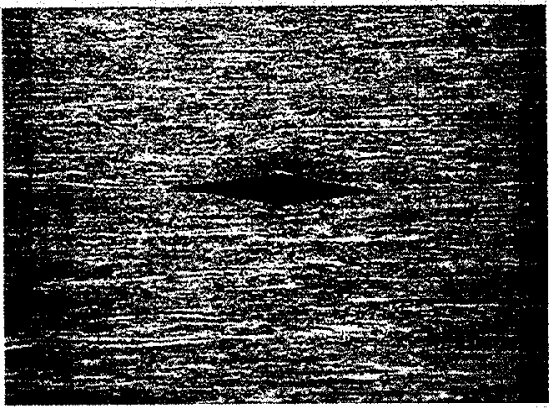

a)

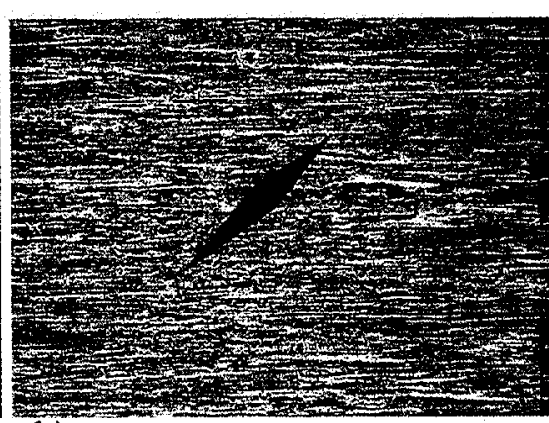

b)

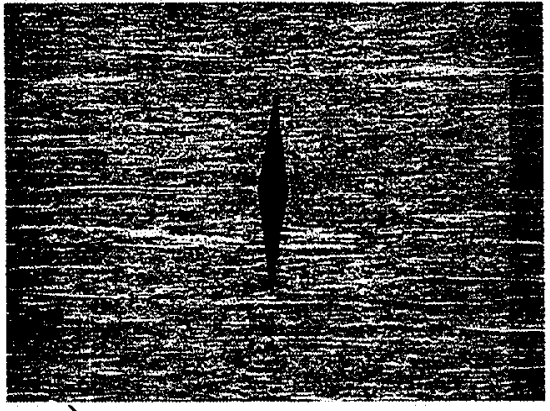

c)

Figure 2. Knoop-hardness characterizations of the as-extruded ODS-Fe $\mathrm{Al}_{3}$ rods in the a) parallel $\left.\left(0^{\circ}\right), b\right)$ inclined $\left(45^{\circ}\right)$, and c) perpendicular (900) orientations.

\section{As-extruded Texture Anisotropy}

The ODS-Fe $3 \mathrm{Al}$ powder extrusions exhibited an extreme texture anisotropy, as observed earlier for cast and extruded $\mathrm{Fe}_{3} \mathrm{Al}$ base alloys [5]. A strong $\{011\}<\mathrm{uvw}>$ fiber texture was observed along the extrusion axis, as recorded via X-ray diffraction peaks from transverse and 
longitudinal sections. A direct comparison of the (022) diffraction peaks taken as a general measure of stored energy, Figure 3, indicated diminishing line broadening with extrusion temperature. Several observations are apparent from such measurements: 1) the extrusions show an extreme anisotropy of (011) diffraction intensity in the longitudinal and transverse directions for each of the extrusions, and 2) the relative anisotropy increases with extrusion temperature, and 3$)$ the $(011\}<u v w>$ fiber texture is progressively stronger with extrusion temperature.

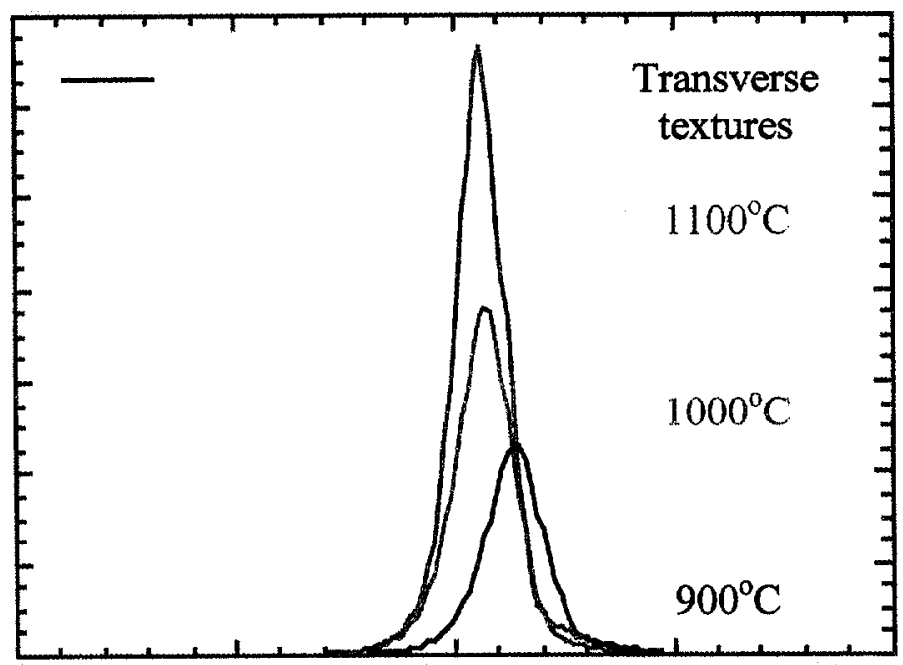

Figure 3. Comparison of (022) textural alignment with increasing extrusion temperature.

\section{$\underline{\text { Recrystallization Kinetics }}$}

In this first iteration, recrystallization kinetics was studied only for the $900^{\circ} \mathrm{C}$ extrusion, of a lower extrusion ratio of 9.8: 1 . Samples were spark machined from the rod cross-section and heattreated in air using a muffle furnace at $1100-1300^{\circ} \mathrm{C}$ for 1 hour. Figure 4 shows the respective optical micrographs of longitudinal sections of as-extruded, and the heat-treated specimen. Figure 5 shows the hardness response of the heat-treated samples where the as-extruded hardness of $530 \mathrm{DPH}$ falls to about $340 \mathrm{DPH}$ for the specimen treated at $1300^{\circ} \mathrm{C}$. A large drop in strength occurred at $1100^{\circ} \mathrm{C}$ in the recovery stage, where no appreciable grain growth was observed. We also noted that a small hardness plateau was observed in the $1200-1250^{\circ} \mathrm{C}$ temperature range, beyond which the hardness continued to decrease, along with the observation of exaggerated grain growth. While complete recrystallization was obtained at $1300^{\circ} \mathrm{C}$, this was accompanied by increased void formation in the solid rods. Thus, the processing parameters required a revision, in the following iteration, to enhance the kinetics, and reduce the recrystallization temperature. 

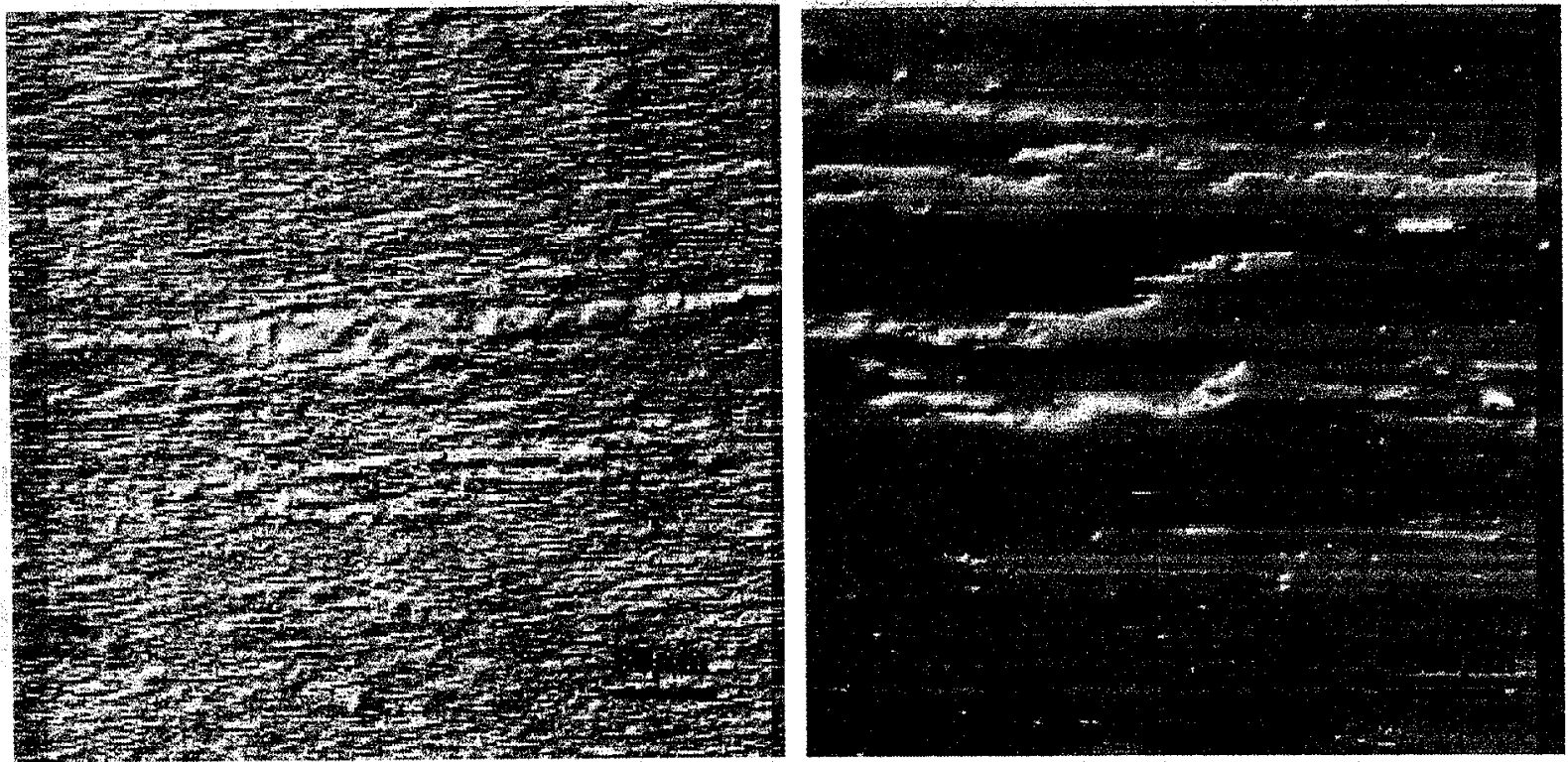

Figure 4. Optical micrographs of a) as-extrudled rod, and b) heat-treated at $1300^{\circ} \mathrm{C} / 1 \mathrm{hr}$.

Effect of Recrystallization Temperature on Mechanical Response

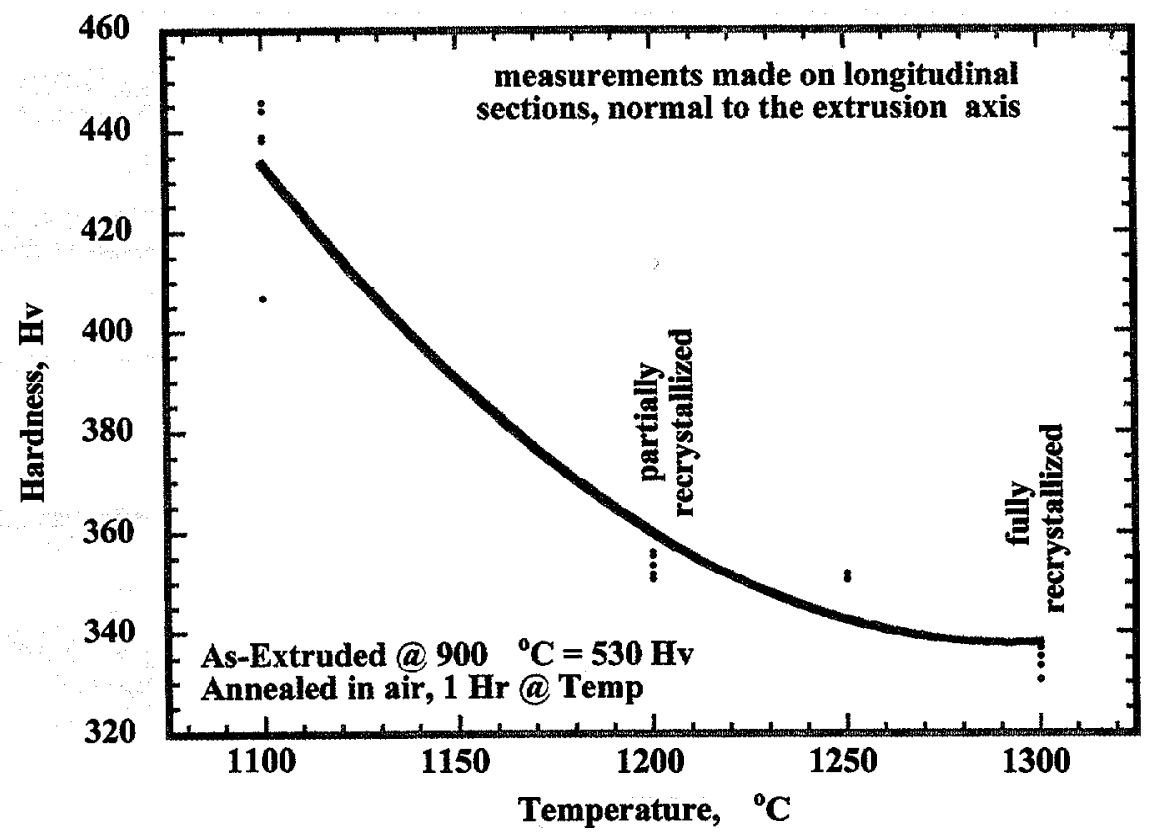

Figure 5. Vickers Hardness decay in response to the recrystallization heat-treatments.

\section{Recrustallization Kinetics with Pre-Strain}

A set of specimens was deformed in compression ( $2 \approx 8 \%, 16 \%$ ), along' the prior extrusion axis, at strain rates of $\approx 10^{-3} \mathrm{sec}^{-1}$. The specimens exhibited cracking along the compression axis, but were nonetheless heat-treated at $1100^{\circ} \mathrm{C}$ and $1200^{\circ} \mathrm{C}$ for one hour. Figure 6 shows hardness response due to the various thermal treatments. A small amount of prestrain was particularly helpful at the lower temperatures of $1100^{\circ} \mathrm{C}$ in promoting grain growth, but this effect was essentially non-existent for treatments at $1200^{\circ} \mathrm{C}$. Figure 7 shows a direct comparison of the 
longitudinal section microstructures of the as-extruded, as heat-treated, and pre-strained + heattreated samples, where the latter exhibited a grain size of the order of $25 \mu \mathrm{m}$. It was deemed likely that such pre-straining, or increasing the extrusion deformation strain, may be employed to accelerate the recrystallization kinetics, as attempted in iteration 2 .

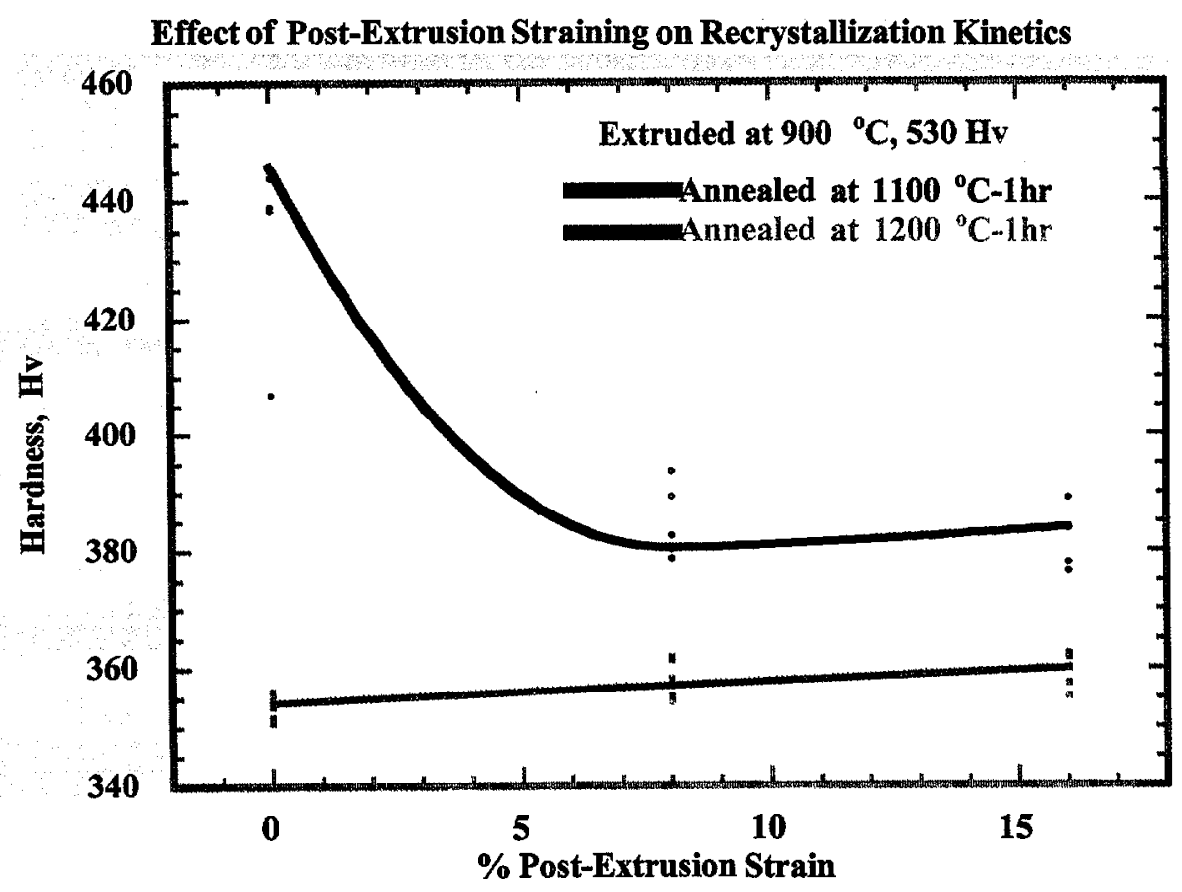

Figure 6. Hardness response of recrystallized specimens with and without pre-straining.
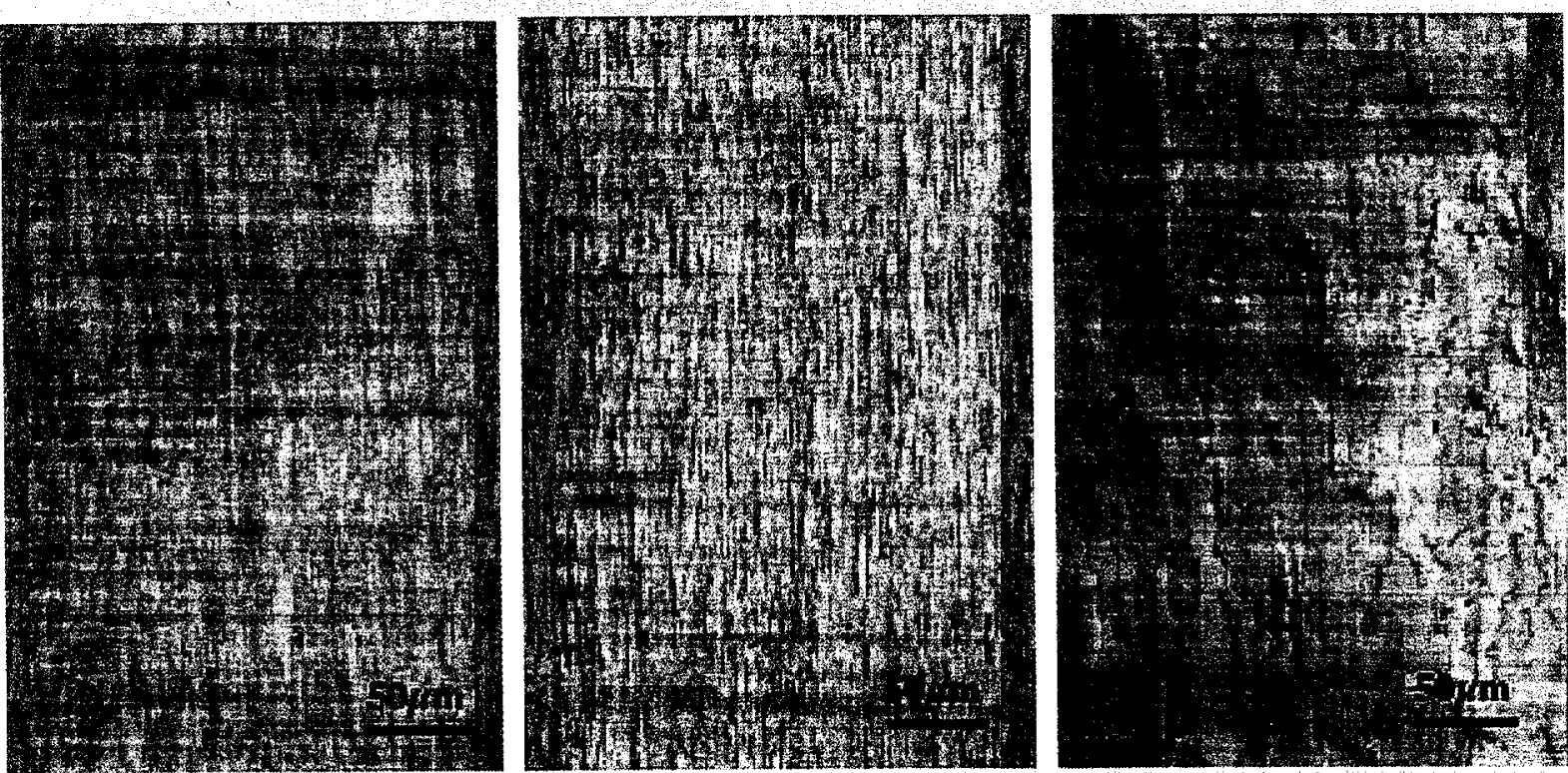

Figure 7. Comparison of a) as-extruded, b) heat treated at $1100^{\circ} \mathrm{C}-1 \mathrm{hr}$, and c) pre-strained and heat-treated at $1100^{\circ} \mathrm{C}-1 \mathrm{hr}$. 


\section{Progress: Iteration 2}

At the conclusion of the first iteration, the broad parameters of extrusion consolidation were identified.. Furthermore, it was shown that the recrystallization kinetics of an as-extruded stock material could be altered via post-extrusion straining techniques, as illustrated in Figures 6-7. However post-extrusion straining bears a certain cost, and thus a revised extrusion schedule was attempted on a second batch of extrusions to incorporate greater deformation strain.

In this second iteration, powder consolidation extrusions of PMWY-1, PMWY-2 and PMWY-3 material batches were carried out in carbon steel billets. Each of the carbon steel cans measured 51-mm OD x $6.4 \mathrm{~mm}$ wall x $125 \mathrm{~mm}$ length (2-in x 0.25-in x 5-in). The cans were filled with powder, evacuated and sealed. A total of three cans were prepared for direct consolidation at a $16: 1$ extrusion ratio, at $1000^{\circ} \mathrm{C}$, the details of which are provided in Table.3.

Table 3: Extrusion consolidation parameters for PMWY-13 powders

\begin{tabular}{|c|c|c|c|c|c|}
\hline \multicolumn{2}{|c|}{ Fxtrusion } & \multicolumn{2}{|c|}{ Die Size } & \multirow{2}{*}{$\begin{array}{c}\text { Area } \\
\text { Reduction }\end{array}$} & \multirow[b]{2}{*}{ Tonnage } \\
\hline Material & Temperature & $\mathrm{mm}$ & inch & & \\
\hline PMWY-1a & 1000 & 12.7 & 0.50 & $16.0: 1$ & $\approx 310$ \\
\hline PMWY-2a & 1000 & 12.7 & 0.50 & 16.0:1 & $\approx 290$ \\
\hline PMWY $-3^{a}$ & 1000 & 12.7 & 0.50 & $16.0: 1$ & $\approx 290$ \\
\hline
\end{tabular}

a5 $\mathrm{lmm}$ (2.0 in) billets for solid rod extrusion;

\section{$\underline{\text { As-extruded Texture Anisotropy }}$}

A strong $(011\}<$ uvw $>$ fiber texture was observed along the extrusion axis for each of the extruded rods of PMWY-1, PMWY-2, and PMWY-3 materials. A direct comparison of the (022) diffraction peaks for the transverse and longitudinal sections of the extruded rods is shown in Figure 8a-b. Results indicated that the textural alignment was the strongest for PMWY-1 and the weakest for PMWY-2. A further examination of the transverse versus longitudinal textures in each of the rods indicated that PMWY-1 exhibited the maximum anisotropy of $\approx 25$ whereas this anisotropy was only of the order of 8-10 for the PMWY-2 extrusion. This variation in anisotropy is not well understood, particularly as the extrusion parameters were essentially identical for all the three bars. Nonetheless, these parameters are routinely tracked in an effort to establish correlations with recrystallization kinetics and characteristics.

\section{$\underline{\text { Recrystallization Kinetics }}$}

A marked improvement in recrystallization kinetics was observed with this increased extrusion ratio. All the rods exhibit partial to complete recrystallization (grain size $\approx 1-2 \mathrm{~mm}$ ) with the heat treatment schedule not exceeding 10 hours at $1200^{\circ} \mathrm{C}$. For brevity, the grain growth behavior of PMWY-1 and PMWY-2 rods is shown in Figures 9 and 10, respectively. In the cross- section view of Figure 9, the outer region is recrystallized, while the core (about 50\%) is 


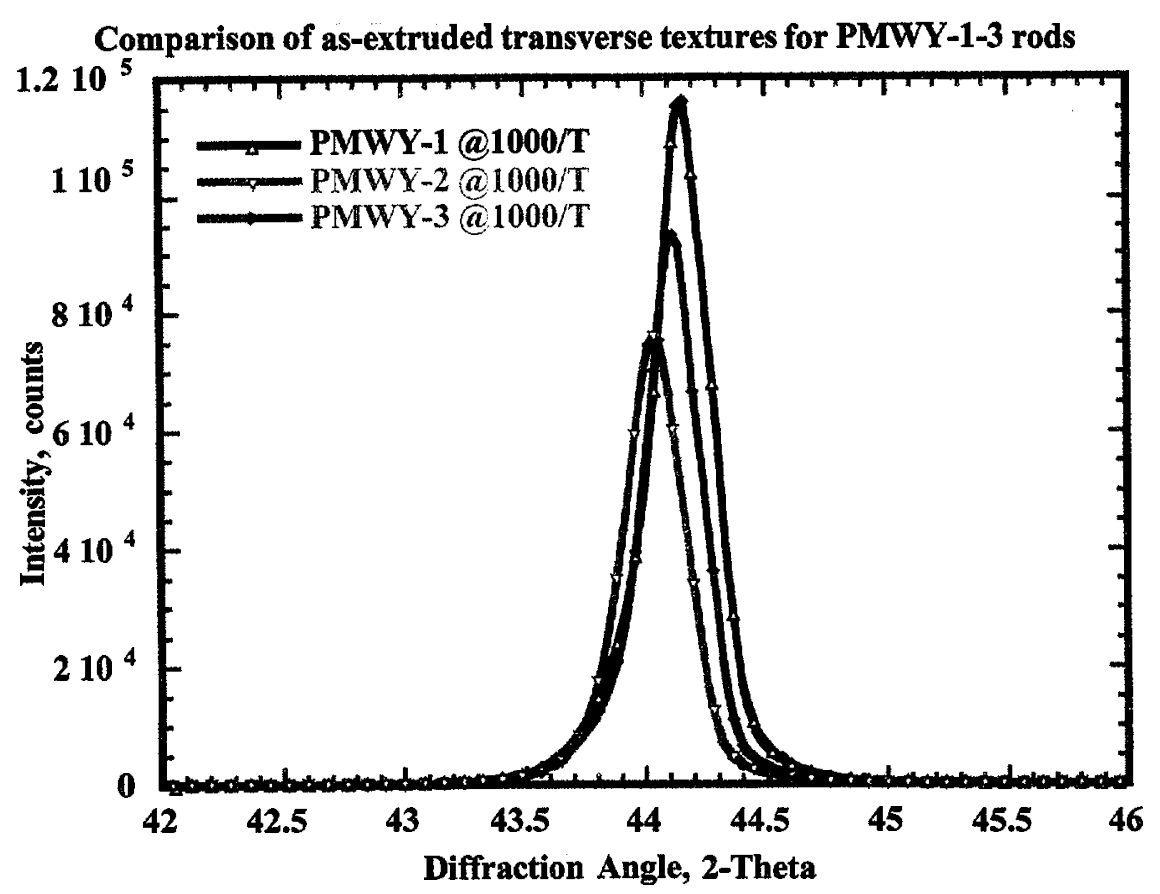

Comparison of as-extruded longitudinal textures for PMWY-1-3 rods

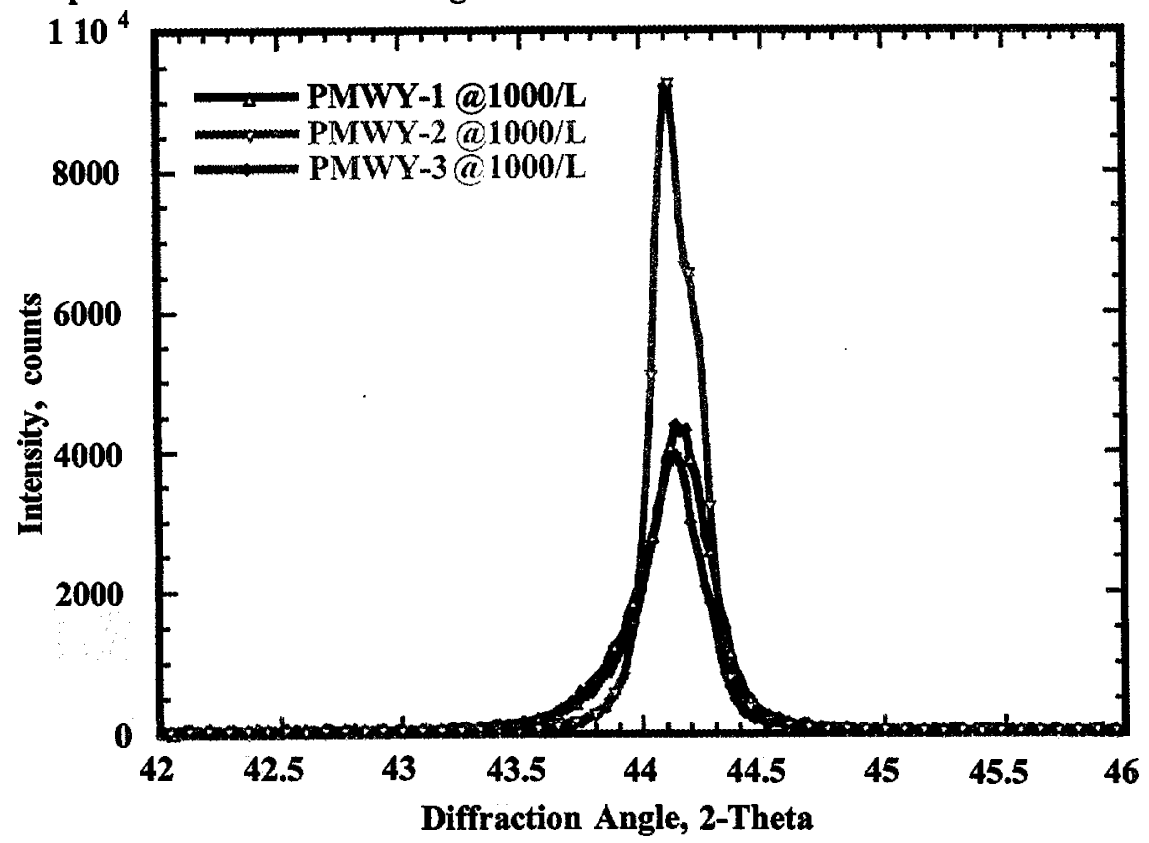

Figure 8. Comparison of (022) texture alignment in the a) transverse and b) longitudinal sections of PMWY-1, PMWY-2 and PMWY-3 extruded rods.

essentially un-recrystallized. However, for the PMWY-2 material, Figure 10, the exterior is essentially a single grain, and the central section is comprised of multiple grains, with grain size of the order of $1-2 \mathrm{~mm}$. Furthermore, the grain shape morphology is extremely contorted, with inter-penetrating segments. 

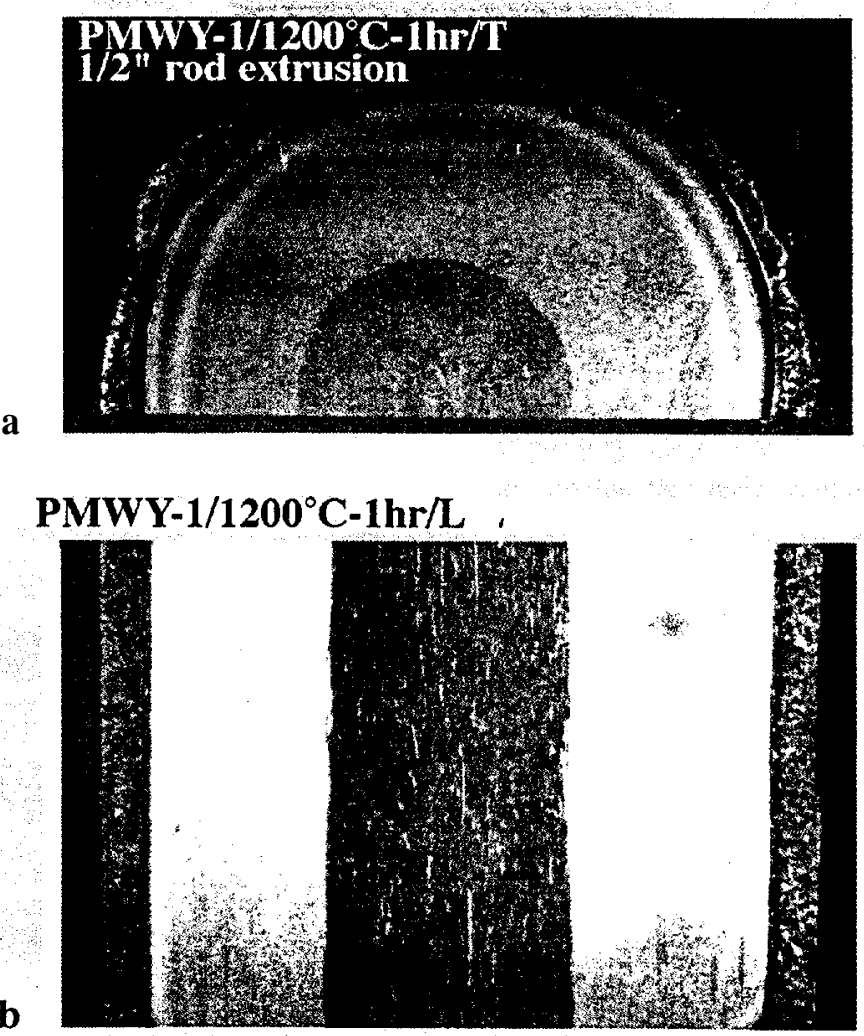

Figure 9. Optical micrographs of a) transverse, and b) longitudinal sections of the $1 / 2^{\prime \prime}$ extruded rod of PMWY-1 material, heat-treated at $1200^{\circ} \mathrm{C}-1 \mathrm{hr}$.

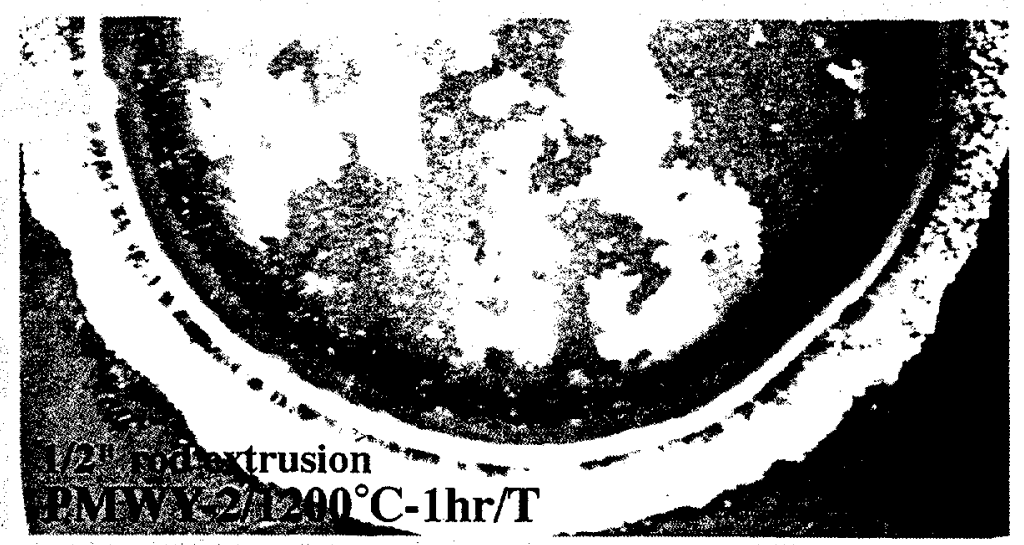

Figure 10. Optical micrographs of transverse section of the $1 / 2$ " extruded rod of PMWY2 material, heat-treated at $1200^{\circ} \mathrm{C}-1 \mathrm{hr}$.

The interpenetrating nature of the grains is further illustrated in Figure 11, as extracted from the transverse and longitudinal sections of the PMWY-2 sample. The grains essentially exhibit a cactus like structure with the net result of providing mechanical interlocking between adjacent grains. The etching contrast in the cross-section view of Figure 10a,b indicates several such interpenetrating islands. Such features are considered important from the viewpoint of developing creep-resistant materials, and will be particularly examined in Task 4 of this program. 


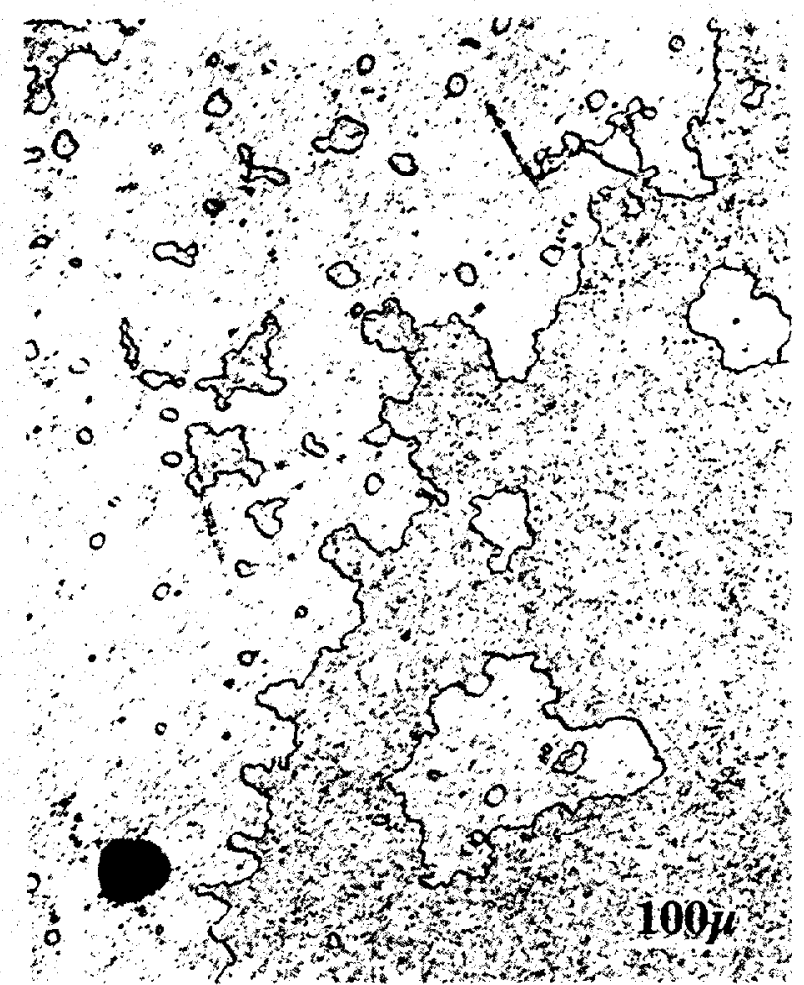

a)

Figure 11. Optical micrograph of the interpenetrating recrystallized/unrecrystallized grain structure in a) transverse, and b) longitudinal sections of the extruded PMWY-2 rods. (Heat-treatments conducted in the $1100^{\circ}-1200^{\circ} \mathrm{C}$ range). The outer section (left) is recrystallized while inner section remains un-recrystallized in (a).

\section{Progress: Iteration 3}

Following the second iterative process, it was concluded that the modified extrusion parameters continued to yield sound extruded stock, with a marked increase in recrystallization kinetics. Thus large grain size grain sized material was obtained by routine heat-treatments in the 1100-1200" range, with hold times of less than 100 hours.

In this third iteration, the process parameters developed and refined in iterations 1 and 2 for rod stock, were applied to annular extrusions in an effort to directly produce tube stock. We note here that annular extrusions were a modification prescribed and accepted during the course of this research program. Typically tube products are produced via a two stage process, i.e., the first step involves creating a bulk ingot of a cylindrical cross-section, which is then re-worked to a hollow tube using different production methodologies. For specialty alloys and materials, this process typically involves drilling a center hole (i.e., gun drilling) before sizing the tube to required dimensions. In our modified process, it was proposed to combine the consolidation step with the tube drilling step via the use of an annular extrusion can. The relative manufacturing advantages and disadvantages of this single step process are illustrated briefly in Figure 12.

The benefits of this single step process are readily apparent, and four different extrusions were attempted as described in Table 4. Thus about 6-8 Ft. lengths of 1-3/8" diameter, 1/8" wall thickness, ODS-Fe $\mathrm{Al}$ tubes were produced via the single step extrusion consolidation process. 


\section{Comparsion of Tube Extrusion Methodologies}

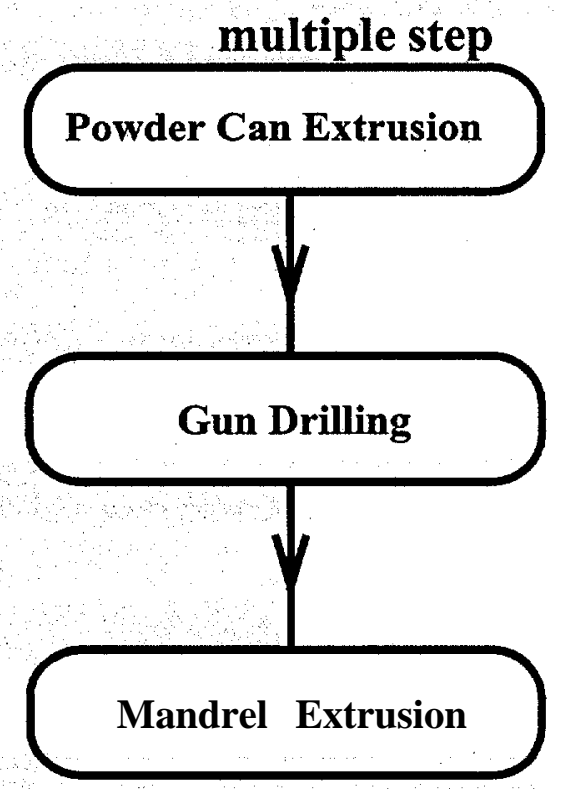

\section{Advantages:}

Clean inner surface

Better dimensional tolerance

Disadvantages:

multiple heating/extrusion steps

poor product yield

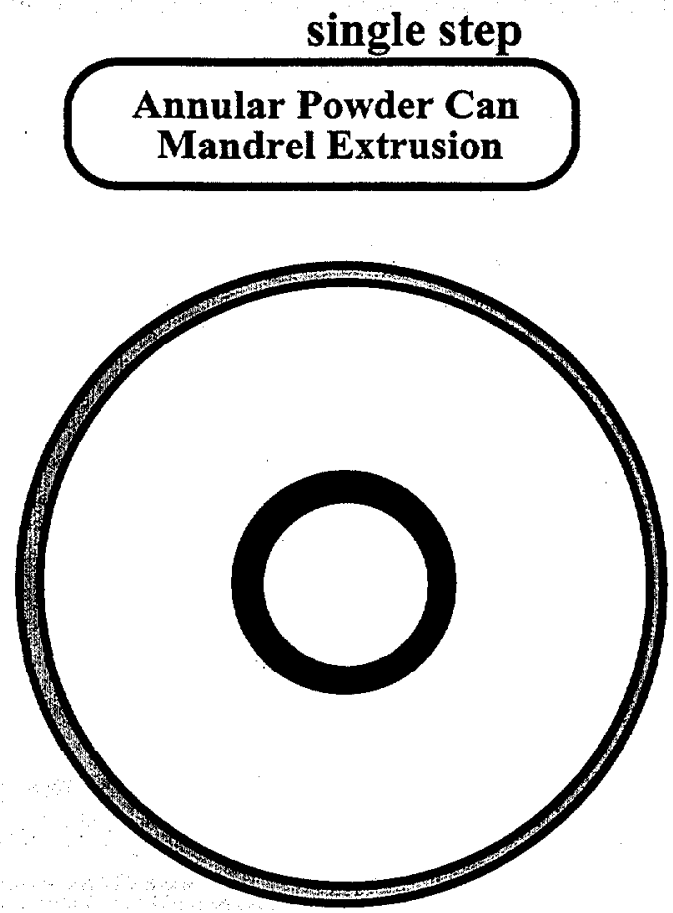

\section{Advantages:}

energy efficient manufacturing

improved product yield

Disadvantages

annular can design complexities

inside surface can layer removal

Figure 12: Comparison of single vs. multiple step extrusion consolidation methodologies.

Table 4: Tube extrusion consolidation parameters for PMWY-I-3 powders

\begin{tabular}{||c|c|c|c|c|c||}
\hline \multicolumn{2}{|c|}{ Fxtrnsinn } & Die. Size & Mandrel Size & Area & Area \\
\hline Material & Temperature & inch & inch & Reduction & Tonnage \\
\hline & & & & & \\
\hline PMWY-1 & $1000^{\circ} \mathrm{C}$ & $\approx 1.375$ & 1.00 & $\approx 16.0: 1$ & NA \\
\hline PMWY-2 & $1000^{\circ} \mathrm{C}$ & $\approx 1.375$ & 1.00 & $\approx 16.0: 1$ & NA \\
\hline PMWY-2 & $1000^{\circ} \mathrm{C}$ & $\approx 1.375$ & 1.00 & $\approx 16.0: 1$ & NA \\
\hline PMWY-3 & $1000^{\circ} \mathrm{C}$ & $\approx 1.375$ & 1.00 & $\approx 16.0: 1$ & NA \\
\hline \hline
\end{tabular}

${ }^{a} 102 \mathrm{~mm}(4.0$ in) billets for thin-walled tube extrusion 
Figure 13 shows a set of tubes in the as-extruded as well as in the surface finished condition. The surface finishing is intended to remove only the outside steel case, and no attempt was made to remove the inside steel case. The tubes were of sound quality, and exhibited no cracking and/or damage after routine machining operations.
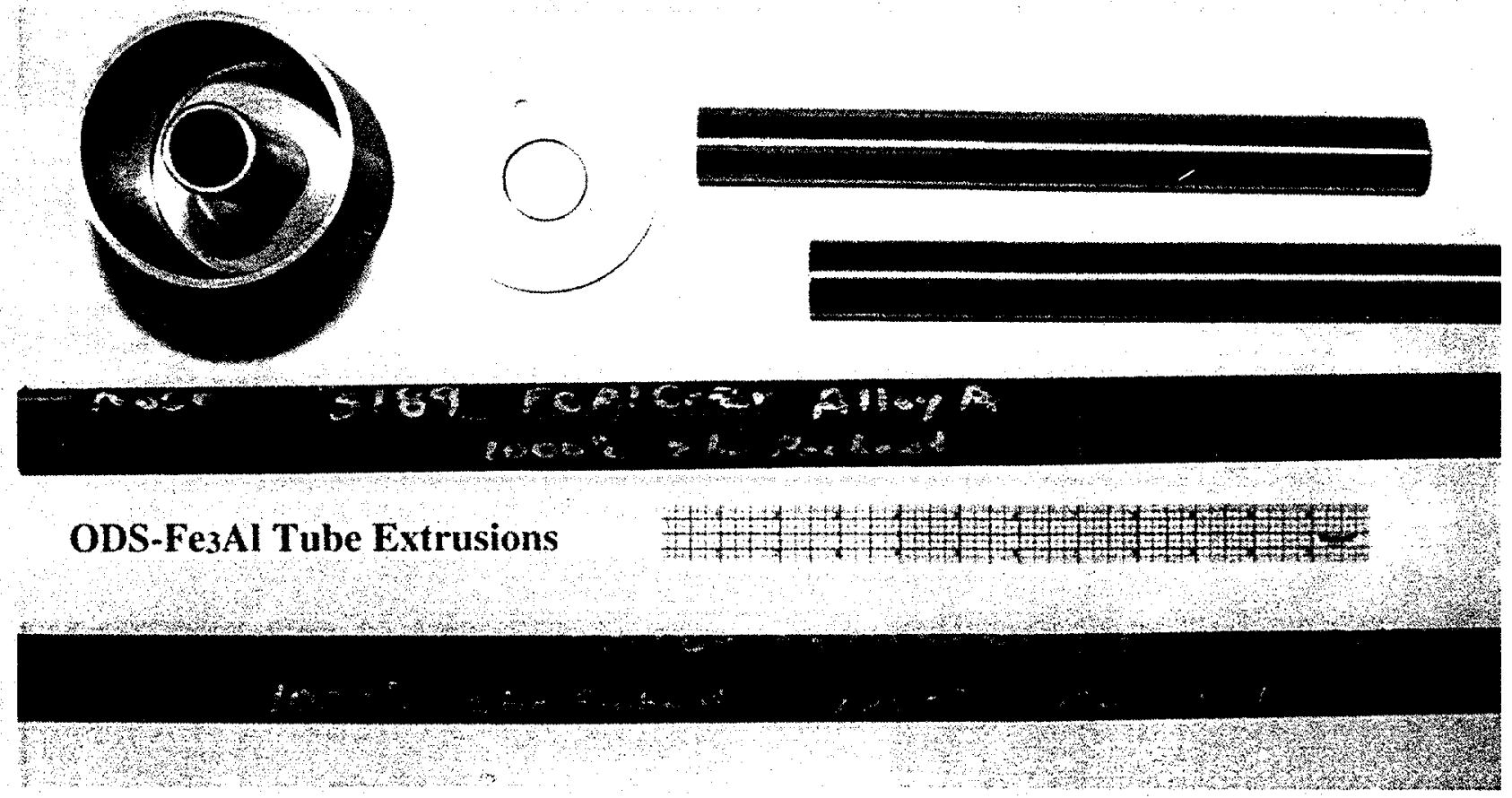

Figure 13. Assorted ODS-Fe $3 \mathrm{Al}$ tubes in the as-extruded (below), and surface finished (top) condition, as produced from an annular can (top left) consolidation methodology.

\section{Hardness Properties \& Recrystallization Kinetics}

The micro-hardness measurements on longitudinal sections of the as-extruded, and the recrystallized tubes, are illustrated in Figure 14. The as-extruded hardnesses were of the order of 450-480 DPH, with PMWY-1 material being the hardest and PMWY-3 the softest. In previous iterations, it was ascertained that large recrystallized grains could be produced by heat-treatments in the $1100^{\circ} \mathrm{C}-100 \mathrm{hrs}$ to $1200^{\circ} \mathrm{C}-10$ hours range. Thus, in this iteration, the heat-treatment schedules were focused to three sets of conditions as; i) $1100^{\circ} \mathrm{C}$ for $100 \mathrm{hrs}$, ii) $1200^{\circ} \mathrm{C}$ for $1-\mathrm{hr}$, and iii) $1200^{\circ} \mathrm{C}$ for $10 \mathrm{hrs}$.

The heat-treated tubes yielded nearly flat (i.e., stable) hardness profile for the three heattreatment schedules, Figure 14, with the exception of PMWY-2 tubes heat-treated at $1200^{\circ} \mathrm{C}-1 \mathrm{hr}$ exhibiting some softening at the extended hold time. This flat profile was concomitant with a recrystallized state, similar to that observed previously for 1/2" rod extrusions (see Figure 5, iteration I). For example PMWY-1 had the highest level of interstitial impurities and PMWY-3 the least, which correlated with PMWY-1 exhibiting a higher micro-hardness in the as-extruded 
and the heat-treated conditions. This correlation with interstitial impurity (introduced during the milling process) points to a possible avenue of additional strength improvements.

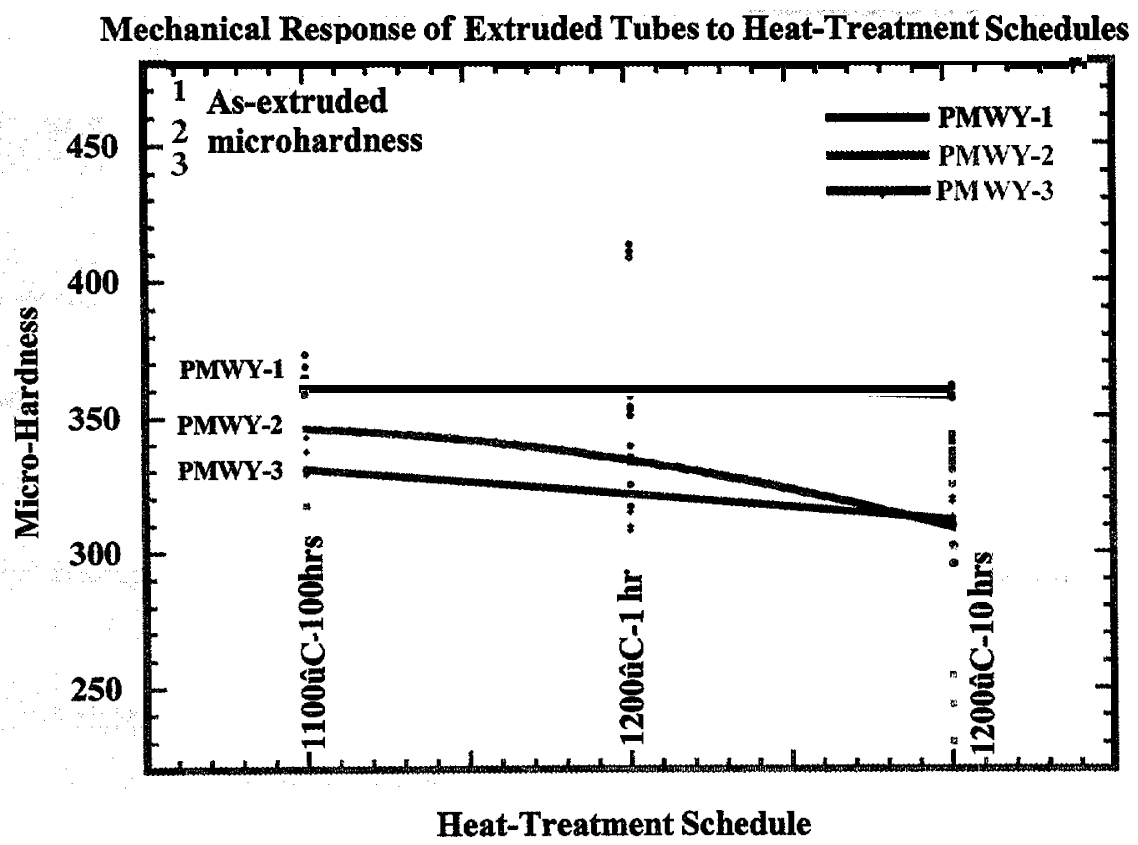

Figure 14. Material microhardness response in the as-extruded, as well as recrystallized state, for the PMWY-1, PMWY-2 and PMWY-3 extruded tubes. Note that the near flat hardness profile indicates a stable microstructural state for all the powder batches.

\section{Recrvstallized Grain Shapes \& Morphologies}

For the sake of brevity, we report here a single set of longitudinal and transverse micrographs for the PMWY-1, PMWY-2 and PMWY-3 tubes heat-treated at $1200^{\circ} \mathrm{C}$ for $1 \mathrm{hr}$. A generic view of the entire cross-section of the sectioned tubes is shown in Figure 15, indicating large-scale gram growth along the tube circumference.

Figure 16a-b shows the longitudinal and transverse views of the PMWY-1 tube respectively, over the entire wall-thickness, including the exterior (at left) and interior (at right) steel-case. A reaction zone about $200 \mu \mathrm{m}$ thick was observed on the exterior surface of the Fe3Al tube, and was characterized by grain boundaries aligned roughly along the radial direction. In the Fe3Al tube, three distinct regions are observed over the wall thickness, as illustrated via etching contrast differences in the longitudinal and cross-section views. Note that only the middle region of the tube thickness is recrystallized. The roughly $700 \mu \mathrm{m}$ wide recrystallized zone is bounded by unrecrystallized regions about $500 \mu \mathrm{m}$ and $2000 \mu \mathrm{m}$ wide on the exterior and interior surfaces of the tube respectively. Thus while recrystallization is initiated within the wall thickness (about $25 \%$ of wall thickness), at this temperature, it does not extend to the extremities. Most importantly, these regions are extended along the circumfurential direction, akin to rings fitting over each-other. This grain alignment is particularly noteworthy, for pressurized tubes, where the tangential loading is twice as severe as the longitudinal loading. 

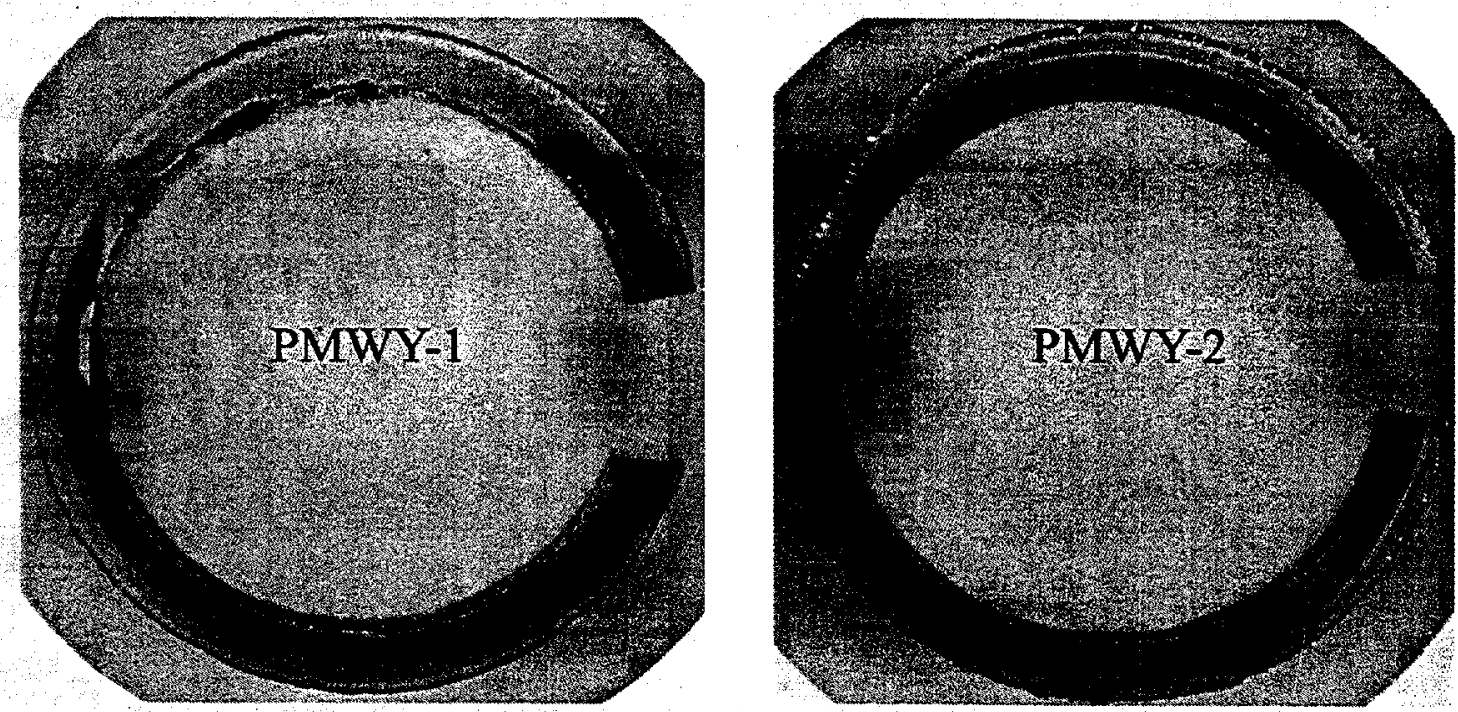

Figure 15. Cross-sectional macro views of the heat-treated a) PMWY- 1, and 2) PMWY2 tubes. Note three distinct regions circumfurentially aligned across the tube wall span.

Figure 17a-b shows the longitudinal and transverse views of the PMWY-2 tube, over the entire wall-thickness, including the exterior (at left) and interior (at right) steel-case. A reaction zone about $225 \mu \mathrm{m}$ thick was observed on the exterior surface of the Fe3Al tube. Once again three regions are observed - a recrystallized region about $2000 \mu \mathrm{m}$ wide is bounded by about $500 \mu \mathrm{m}$ and $700 \mu \mathrm{m}$ wide strips of unrecrystallized regions on the outside and the inside surface respectively. The recrystallized region spans roughly $60 \%$ of the tube wall thickness. Both the exterior and interior extremities of the Fe3Al tube were characterized by the familiar tangentially oriented un-recrystallized regions extending over the entire circumference of the tube. Interestingly the recrystallized region is populated by an assortment of inter-penetrating grains expected to be beneficial to creep response.

Figure 18a-b shows the longitudinal and transverse views of the PMWY-3 tube, over the entire wall-thickness, including the exterior (at left) and interior (at right) steel-case. A reaction zone about $225 \mu \mathrm{m}$ thick is observed on the exterior surface of the Fe3Al tube. Unlike PMWY-1 and PMWY-2 tubes, there were no regions of circumferentially aligned grains. But the entire section thickness is fully recrystallized. Though large jagged and interpenetrating grains were observed throughout the transverse and longitudinal sections, often spanning the entire wall thickness, they did not extend circumferentially. The existence of these inter-penetrating features is expected to beneficially impact creep response. Additionally, PMWY-3 tubes heat-treated at $1100^{\circ} \mathrm{C}-100 \mathrm{hrs}$ and $1200^{\circ} \mathrm{C}-10 \mathrm{hrs}$ (not shown here) also exhibited similar grain morphologies.

The kinetics of grain growth are consistent with the overall interstitial impurity content of the respective powder batches. While recrystallization is initiated in all tube sections for this constant heat-treatment, the increased impurity precipitate content hinders its growth. Thus PMWY-3 with the least impurity exhibits large-scale grain growth while PMWY-2 and PMWY-1 show limited grain growth on account of their increasing impurity content (see Table 1). 


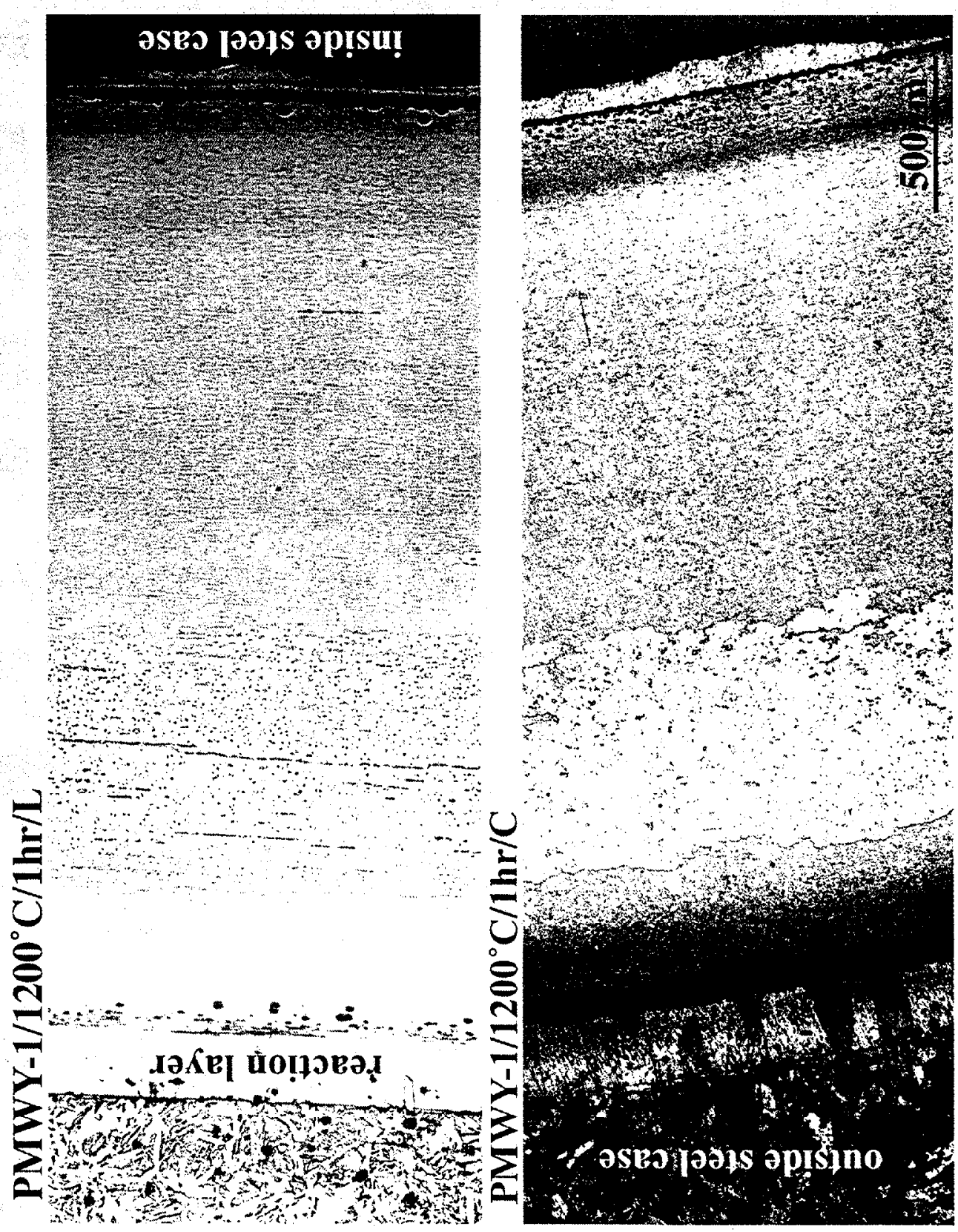

Figure 16. Longitudinal and transverse views of the PMWY-1 tube heat-treated at $1200^{\circ} / 1 \mathrm{hr}$. 

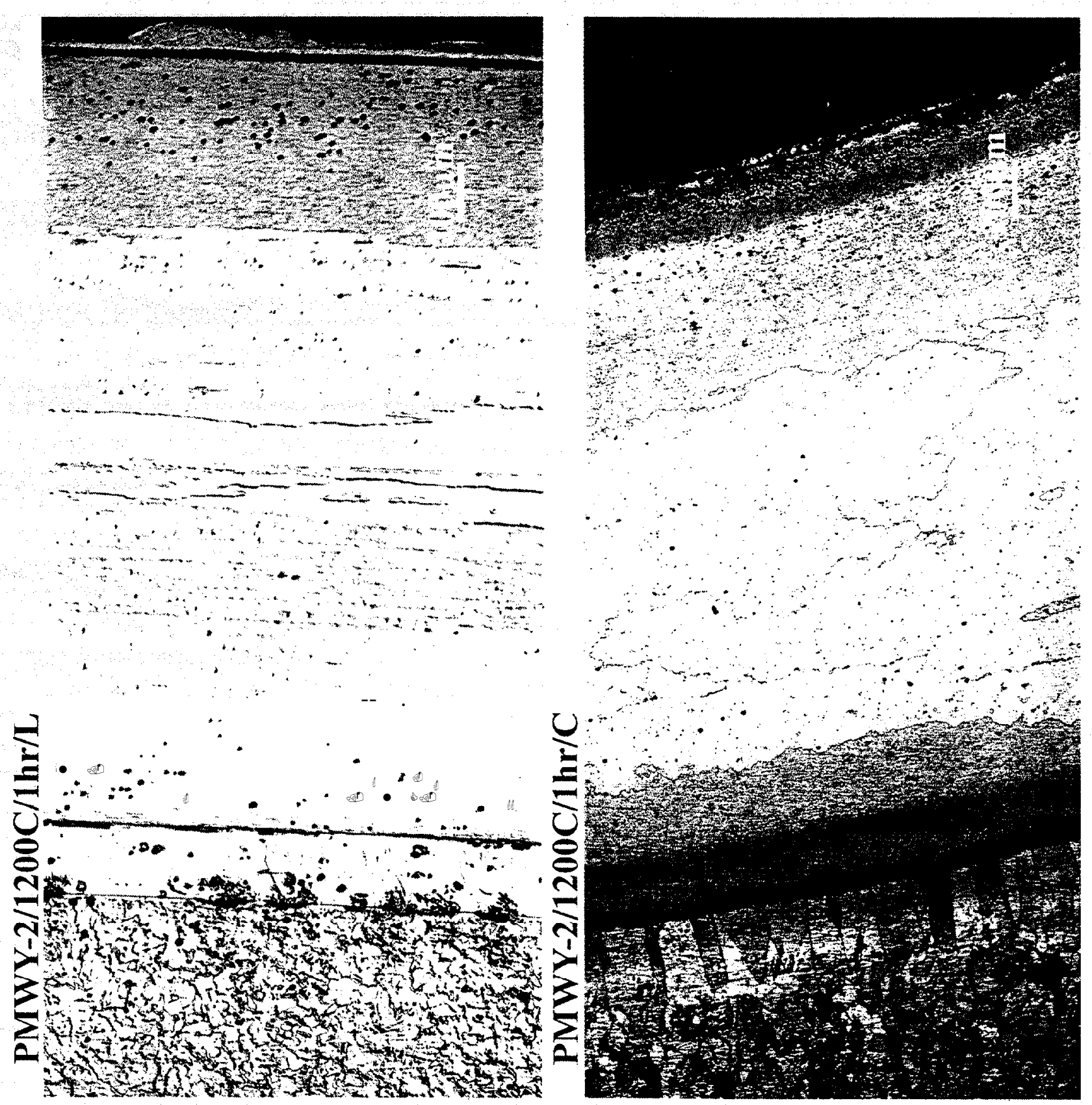

Figure 17. Longitudinal and transverse views of the PMWY-2 tube heat-treated at $1200^{\circ} / 1 \mathrm{hr}$. 

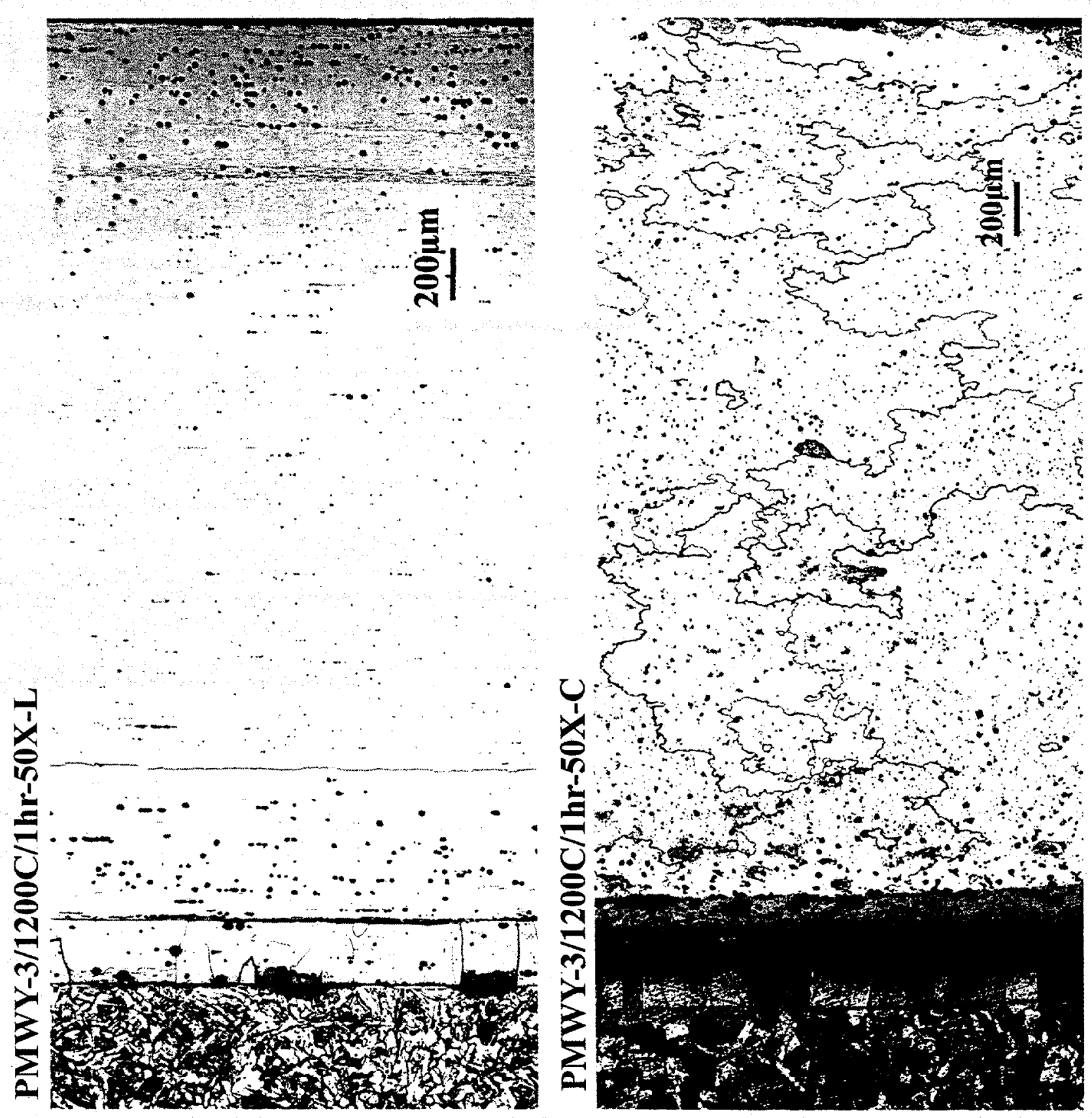

Figure 18. Longitudinal and transverse'views of the PMWY-3 tube heat-treated at $1200^{\circ} / 1 \mathrm{hr}$. 


\section{Progress: Iteration 4}

Following the successful production of 1-3/8" OD extruded and recrystallized tubes in the preceding iteration, detailed microstructural and mechanical properties are examined in the current iteration.

A 10" long piece of each tube (PMWY-1, PMWY-2 and PMWY-3) was cut from the bulk stock and specifically heat-treated in a muffle furnace at $1200^{\circ} \mathrm{C}$ for 1 -hr. Both TEM and mechanical property specimens were extracted from this tube. Thus, in the following sections, unless stated otherwise all samples are taken from these extruded tubes.

\section{$\underline{\text { TEM Microstructures }}$}

Bright Field TEM micrographs of specimens extracted from the heat-treated tubes are shown in Figure 19. The $3 \mathrm{~mm}$ discs were extracted from the wall thickness of the tubing such that foil normal and the extrusion axis are co-incident. With the TEM thin foil perforation expected near the center of the discs, the microstructures shown below are then representative of the center of the tube thickness. Both PMWY-1 and PMWY-2 tubes exhibit a fine-grained structure, Figure $19 \mathrm{a}, \mathrm{b}$, with a $<110>$ fiber texture indicating incomplete recrystallization. However, PMWY-3, Figure 19c, exhibits a coarse grain structure with a $<111>$ fiber orientation. The precipitate distribution in PMWY-3 is bi-modal with the coarser particles exhibiting a cell-type structure on the scale of $1 \mu \mathrm{m}$. This dimension is consistent with the as-extruded grain size and it is suggested that this particle distribution was originally present at the as-extruded grain boundaries.
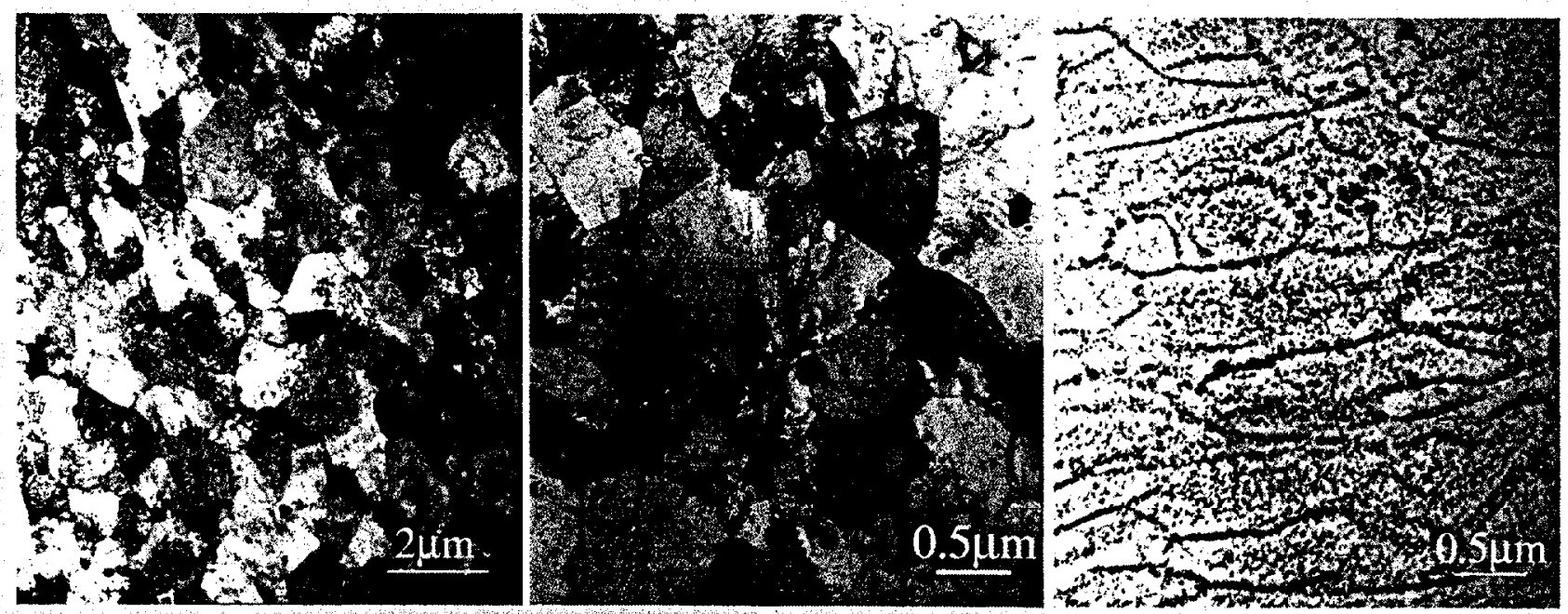

Figure 19. TEM micrographs of a) PMWY-1, b) PMWY-2 and c) PMWY-3 specimens extracted from the heat-treated tubes. The viewing direction is along the extrusion axis.

We note that PMWY-2 often shows'large recrystallized regions or fine grains depending on where the thin foil for TEM studies is extracted. A magnified view of the PMWY-2 sample, Figure 20, reveals that the grains are effectively pinned by fine (Figure 20a) and coarse (Figure $20 \mathrm{~b}$ ) precipitate particles. As shown later the large particles are typically oxides and nitrides of aluminum and are most commonly encountered at the grain boundaries and vertices. 

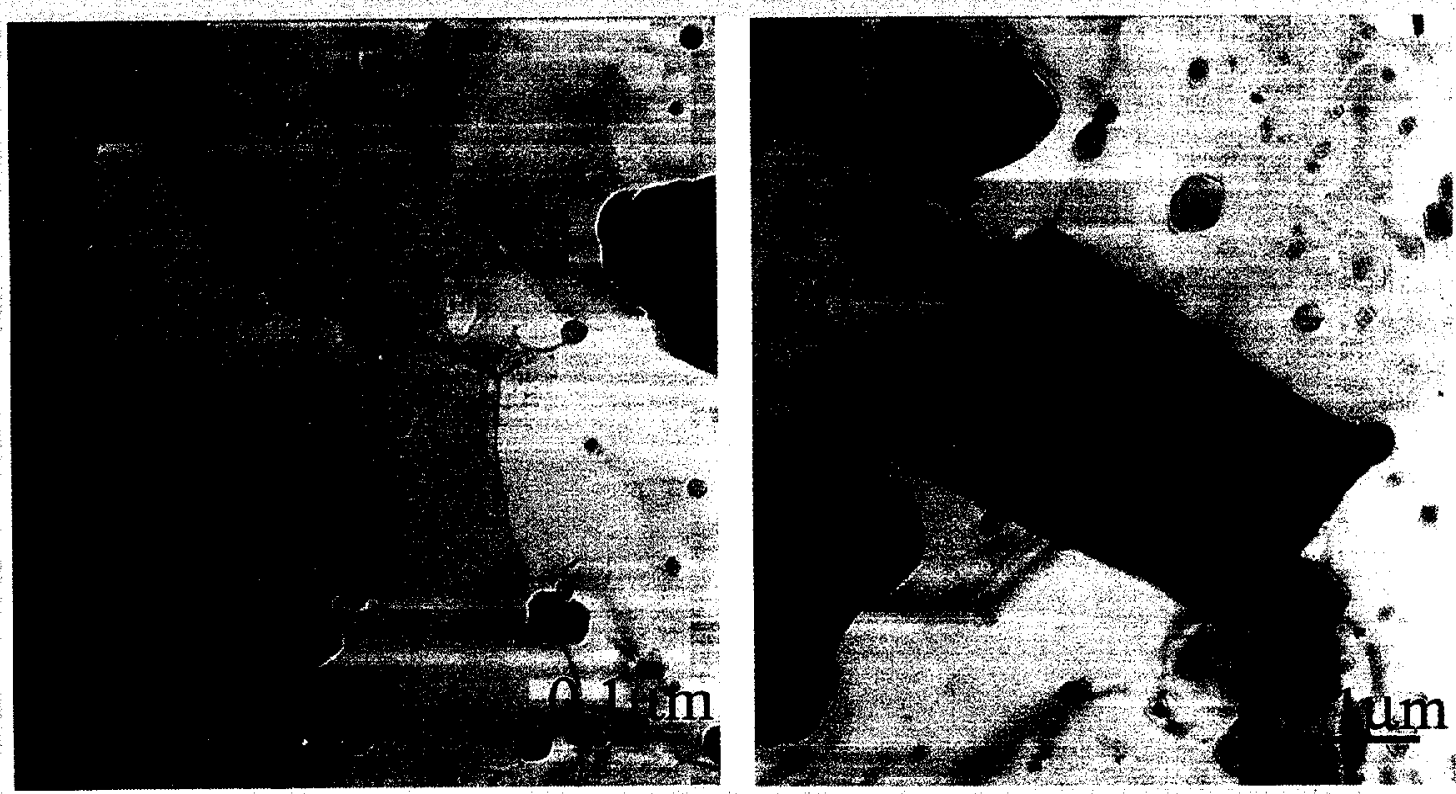

Figure 20. Magnified view of PMWY-2 tube cross-section indicating the pinning of grain boundaries by a) small yttrium oxide, and b) large ( $\mathrm{AlN}$ or $\mathrm{Al}_{2} \mathrm{O}_{3}$ ) precipitate particles.

\section{Precipitate Chemical Analvses}

The precipitate chemistry was analyzed by EDS primarily for as-extruded and heat-treated

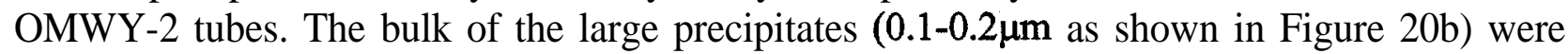
identified as oxides, nitrides of aluminum as shown in Figure 21a,b and Table 5,6. Despite the presence of a healthy $\mathrm{C}$ impurity level (see Table 1) no large carbide precipitates were observed.
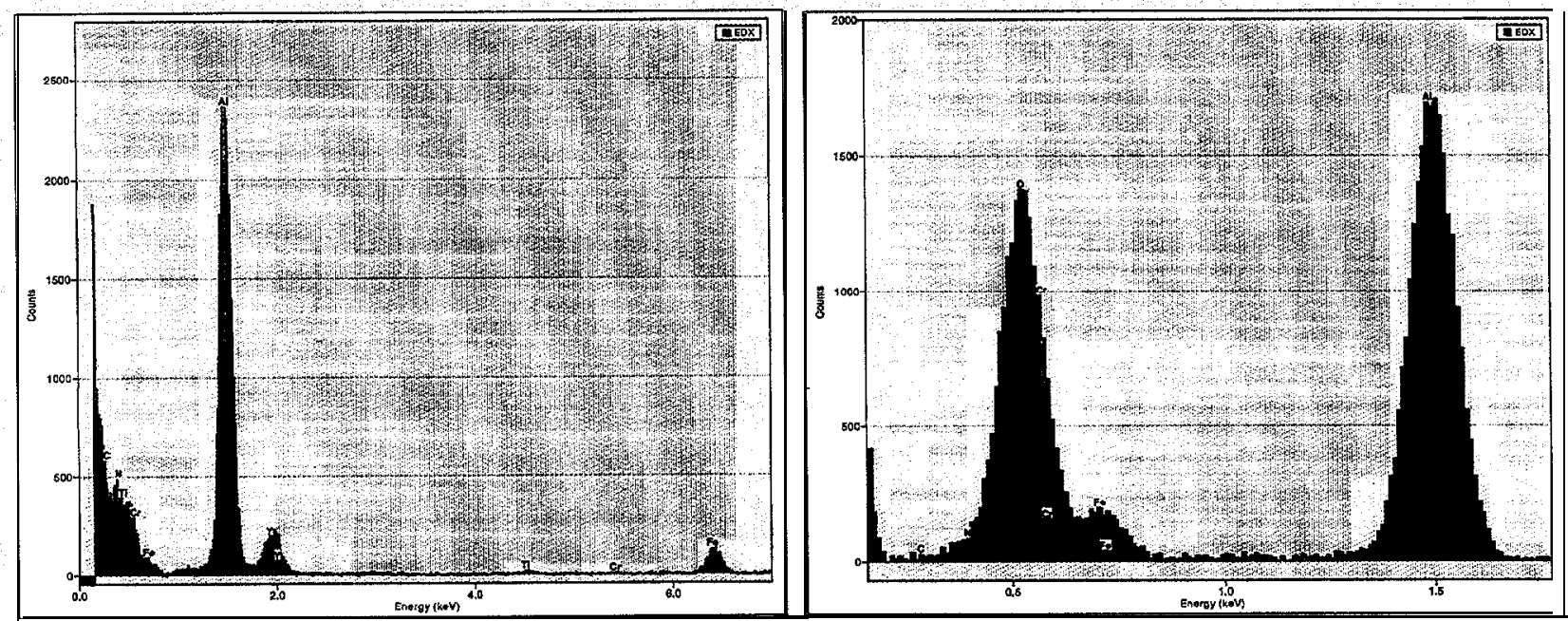

Figure 21. EDS Spectra of a) aluminum nitride, and b) aluminum oxide in PMWY-2 foils. 
Table 5: Chemical Analysis of Aluminum Nitride precipitate (Figure 21a)

\begin{tabular}{|c|c|c|c|c|}
\hline Edge & Intensity & k-factor & Weight \% & Atomic \% \\
\hline N K $\alpha$ & 1793 & 3.920 & 30.62 & 48.91 \\
\hline Al K $\alpha$ & 26617 & 1.039 & 56.98 & 47.26 \\
\hline Ti K $\alpha$ & $\mathbf{f}-1$ & 1.308 & 0.15 & 0.07 \\
\hline Cr K $\alpha$ & 34 & 1.385 & 0.10 & 0.04 \\
\hline Fe K $\alpha$ & 1441 & 1.488 & 4.42 & 1.77 \\
\hline Y K $\alpha$ & 1026 & 3.659 & 7.73 & 1.95 \\
\hline
\end{tabular}

Table 6: Chemical Analysis of Aluminum Oxide precipitate (Figure 21b)

\begin{tabular}{|c|c|c|c|c|}
\hline Edge & Intensity & k-factor & Weight \% & Atomic \% \\
\hline $\mathbf{O ~ K \alpha}$ & $1383 \overline{3}$ & 1.950 & 50.96 & $\mathbf{6 7 . 1 3}$ \\
\hline $\mathbf{A l ~ K \alpha}$ & 18399 & 1.039 & 36.13 & 28.22 \\
\hline $\mathbf{C r ~ K a}$ & 155 & 1.385 & 0.40 & 0.16 \\
\hline $\mathbf{F e ~ K a}$ & 3869 & 1.488 & 10.87 & 4.10 \\
\hline $\mathbf{Y ~ K} \alpha$ & 236 & 3.659 & 1.63 & 0.39 \\
\hline
\end{tabular}

The Yttrium Oxide particles are in general much finer (see Figure 20a) and are often present as complex oxides of aluminum, iron and yttrium. An example spectrum is shown in Figure 22 where the particle is analyzed in Table 7 asyttrium-aluminum-oxide (also known as garnet).

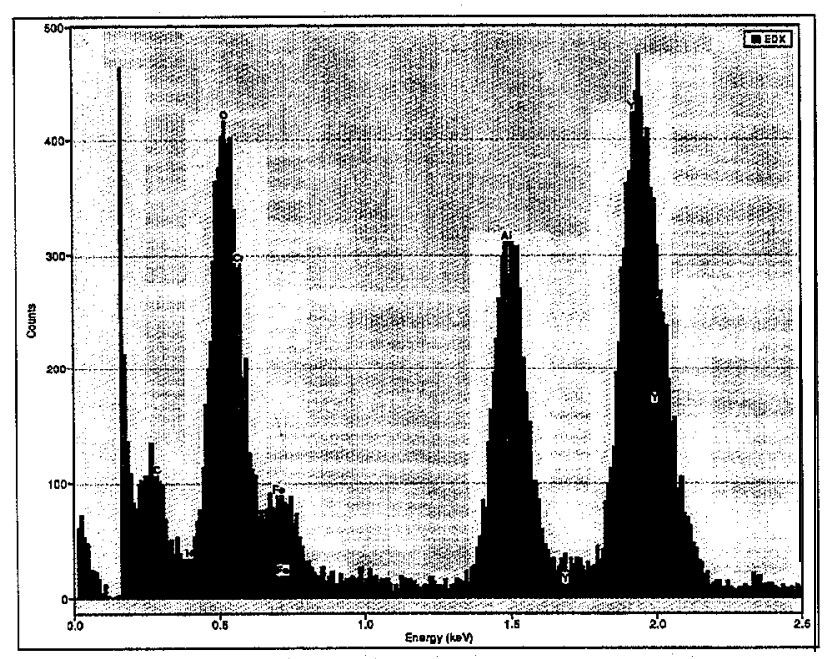

Figure 22. EDS Spectra of yttrium-aluminum-oxide (YAG) in PMWY-2 foils.

Table 7: Chemical Analysis of Yttrium-Aluminum Oxide precipitate (Figure 20a)

\begin{tabular}{|c|c|c|c|c|}
\hline Edge & Intensity & k-factor & Weight \% & Atomic \% \\
\hline O K $\alpha$ & 4289 & 1.950 & 34.01 & 64.54 \\
\hline Al K $\alpha$ & 3284 & 1.039 & 13.88 & 15.62 \\
\hline Cr K $\alpha$ & 24 & 1.385 & 0.14 & 0.08 \\
\hline Fe K $\alpha$ & 1647 & 1.488 & 9.97 & 5.42 \\
\hline Y L $\alpha$ & 4082 & 2.530 & 42.01 & 14.34 \\
\hline
\end{tabular}




\section{Progress: Iteration 5}

\section{High Temperature Mechanical Response}

High temperature tensile properties were examined for ASTM E-8 miniature specimens spark machined from the 1/8" shell thickness of the 1-3/8" O.D. extruded tube. Tensile test were performed at temperature at 'a constant strain rate of $3 \times 10$ " $\mathrm{sec}^{-1}$.

Figure 23 shows the strength and ductility response for recrystallized PMWY-2 tube stock tested over the room temperature to $1100^{\circ} \mathrm{C}$ range. Figure 23a indicates that the material exhibits a strength plateau up to $4000 \mathrm{C}$ with large drops experienced in the $400-800^{\circ} \mathrm{C}$ range. In the anticipated service temperature range of $900-1100^{\circ} \mathrm{C}$ the material response is elastic-fully plastic, with the YS ranging from 8-14Ksi. Figure $23 \mathrm{~b}$ indicates that both ductility and reduction in area (PA) go through a maxima at about $8000 \mathrm{C}$. The change in RA beyond $8000 \mathrm{C}$ is particularly noteworthy. As shown later this is indicative of a change in active deformation mechanism.
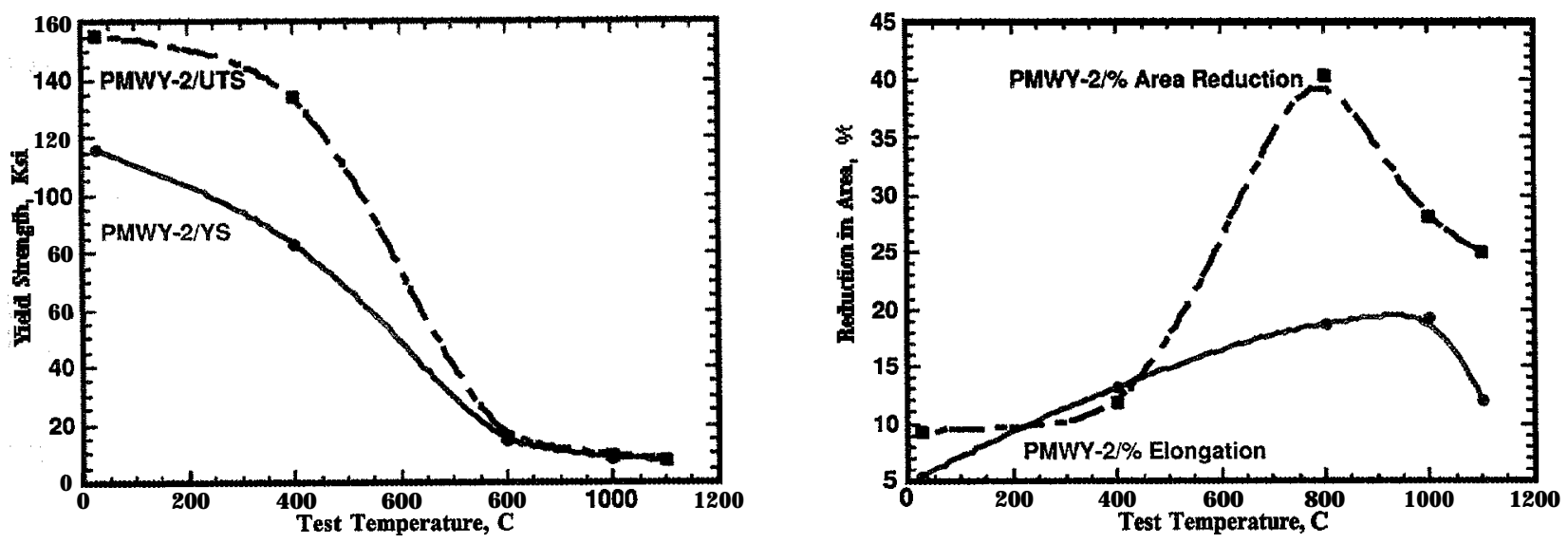

Figure 23. a) Strength and b) ductility response of extruded and recrystallized PMWY-2 stock.

Figure 24 shows the failure microstructures for PMWY-2 tensile coupons (ASTM E-8 specimens with $1 / 2$ " gage length) tested over a range of temperatures at a strain rate of $3 \times 10^{-3} \mathrm{sec}^{-}$ ${ }^{1}$. The material exhibits brittle fracture at the lower temperatures and ductile fibrous fracture at $1000^{\circ} \mathrm{C}$ and above yielding a brittle to ductile transition temperature (DBTT) of about 8000C. The fracture mode transition at about $8000 \mathrm{C}$ reflects a change in deformation mechanism from a dislocation-dominated glide to a diffusion assisted deformation mechanism. For example, the complete necking of figure $24 \mathrm{c}$ indicates dominant dislocation glide mechanisms, and the gradual drop in \%RA (Figure 23b) beyond this temperature suggests subtle shifts in mechanisms operative at this particular strain rate of testing. The maximum \% reduction in area at $8000 \mathrm{C}$ (Figure 23b) is entirely consistent with the chisel shaped fracture evidence of Figure 24c, where the specimen has gage thickness is essentially reduced to a line. Fracture evidence for the $1100^{\circ} \mathrm{C}$ tensile test reveal similar, but finer, features as shown in Figure $24 \mathrm{~d}$. For Brevity only the failure fractures of Pm-2 are illustrated here. Fracture surfaces in PMWY-2 and PMWY3 exhibit essentially similar behavior, with minor differences in strength and ductility levels. 

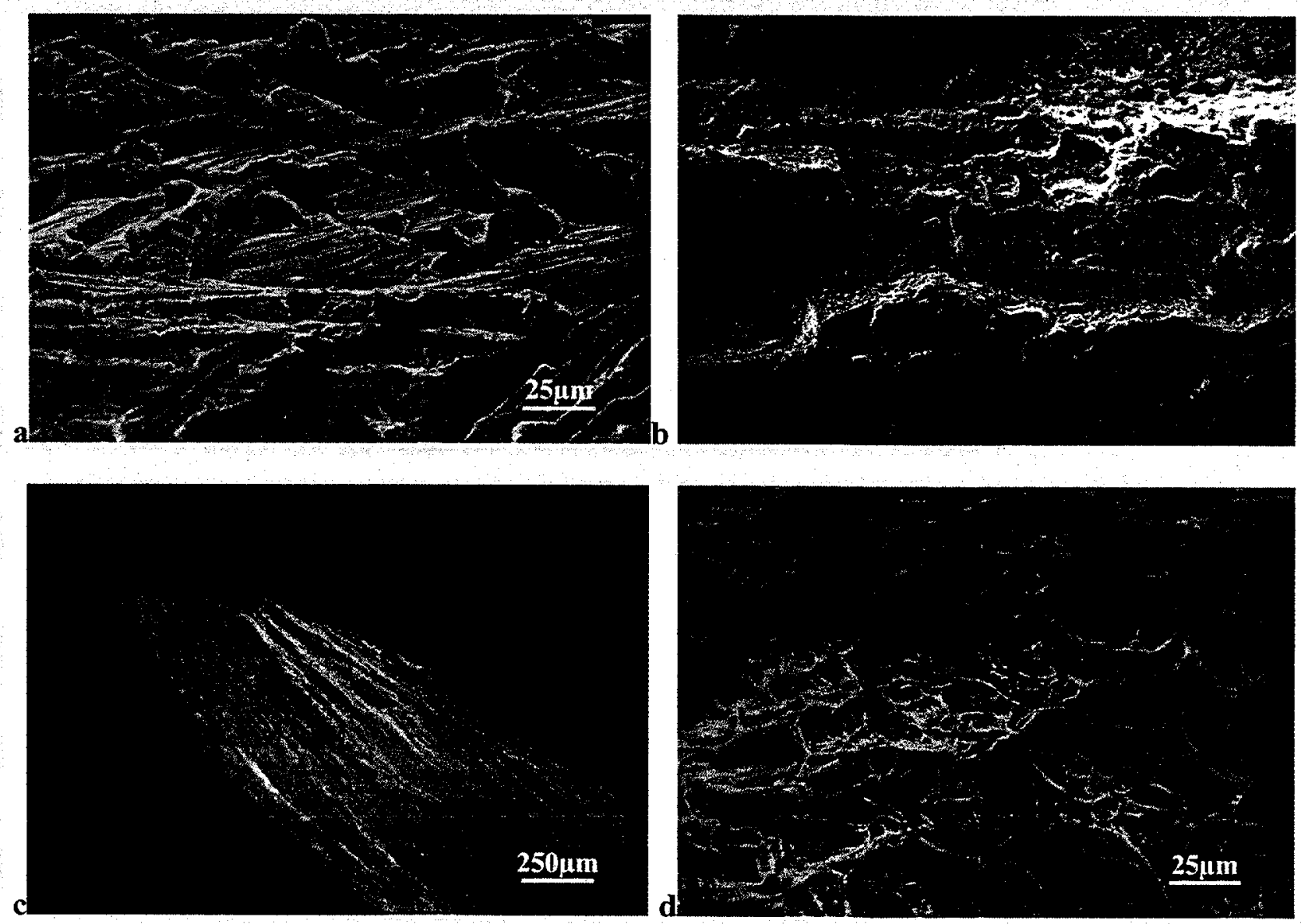

Figure 24. Tensile failures in PMWY-2 specimens tested at a) Room-Temp, b) $400^{\circ} \mathrm{C}$, c) $800^{\circ} \mathrm{C}$, and d) $1000^{\circ} \mathrm{C}$. Note complete necking for the $800^{\circ} \mathrm{C}$ test with a corresponding maximum reduction in area.

With the DBTT established in the previous iteration, the anticipated service temperature identified as greater than $8000 \mathrm{C}$ and the constancy of the fracture mechanism beyond this temperature, further tests were limited to the $800-1000^{\circ} \mathrm{C}$ range for all the three tubes. Tables 8,9 list the complete matrix of tests conducted in the longitudinal orientation and transverse orientations, respectively. In each table, the samples are identified as PMWY-1, PMWY-2 and PMWY-3 and the second identifier is the batch order in which the tests were conducted. The composite behavior of all specimens is for the longitudinal and transverse orientations is given in figures $25 \mathrm{a}, \mathrm{b}$. Using tensile strength as a ranking measure for the peak test temperature of $1000^{\circ} \mathrm{C}$ we note that for longitudinal testing PMWY-3 exhibits the best combination of yield and ultimate tensile strength. Selected samples of PMWY-2 matched the mechanical response of PMWY-3 while PMWY-1 exhibited the poorest response. Because of the significant scatter in mechanical response, it was surmised that possible furnace temperature gradients might cause point-to-point variations in microstructure. As a result, machined ASTM specimens (batch 4) of PMWY-1 and PMWY-2 were heat-treated again at $1200^{\circ} \mathrm{C}-1 \mathrm{hr}$ and retested. We note that PMWY-1 exhibits a modest improvement in strength at the higher $1000^{\circ} \mathrm{C}$ test temperature. Further heat-treatments of such samples are continuing to explore additional improvements in high temperature response. 
Table 8. High Temperature Longitudinal Mechanical Properties for the Extruded Tubes

\begin{tabular}{|c|c|c|c|c|c|}
\hline Sample & Heat Treatment & Test Temp & YS, Ksi & UTS, Ksi & Elongation \\
\hline PMWY-1, 1st* & $1200 \mathrm{C} / 1 \mathrm{hr}$, Air & 800.00 & 14.900 & 18.700 & 25.500 \\
\hline PMWY-1, 2nd* & $1200 \mathrm{C} / 1 \mathrm{hr}$, Air & 800.00 & 15.900 & 18.100 & 30.700 \\
\hline PMWY-1, 3rd* & $1200 \mathrm{C} / 1 \mathrm{hr}, \mathrm{Air}$ & 800.00 & $\mathbf{1 8 . 4 0 0}$ & 18.600 & 23.700 \\
\hline PMWY-1, 4th & $1200 \mathrm{C} / 1 \mathrm{hr}$, Air & 800.00 & 18.900 & 20.100 & 28.500 \\
\hline PMWY-1, 1st* & $1200 \mathrm{C} / 1 \mathrm{hr}$, Air & 900.00 & 10.900 & 11.700 & 30.000 \\
\hline PMWY-1, 2nd* & $1200 \mathrm{C} / 1 \mathrm{hr}, \mathrm{Air}$ & 900.00 & 15.100 & 15.400 & 22.700 \\
\hline PMWY-1, 3rd* & 1200C/1hr, Air & 900.00 & 13.800 & 14.100 & 43.700 \\
\hline PMWY-1, 4th & $1200 \mathrm{C} / 1 \mathrm{hr}$, Air & 900.00 & 13.400 & 13.800 & 30.500 \\
\hline PMWY-1, 1st" & $1200 \mathrm{C} / 1 \mathrm{hr}$, Air & 1000.0 & 7.9000 & 9.1000 & 40 \\
\hline PMWY-1, 2nd* & $1200 \mathrm{C} / 1 \mathrm{hr}, \mathrm{Air}$ & 1000.0 & 8.8000 & 9.3000 & 25.700 \\
\hline PMWY-1, 3rd* & $1200 \mathrm{C} / 1 \mathrm{hr}$, Air & 1000.0 & 9.4000 & 9.7000 & 17.600 \\
\hline PMWY-1, 4th & $1200 \mathrm{C} / 1 \mathrm{hr}, \mathrm{Air}$ & 1000.0 & 9.9000 & 10.400 & 31.000 \\
\hline PMWY-2, 1st* & $1200 \mathrm{C} / 1 \mathrm{hr}, \mathrm{Air}$ & 800.00 & 15.900 & 18.700 & 27000 \\
\hline PMWY-2, 2nd* & $1200 \mathrm{C} / 1 \mathrm{hr}, \mathrm{Air}$ & 800.00 & 18.200 & 18.800 & 37.000 \\
\hline PMWY-2, 3rd* & $1200 \mathrm{C} / 1 \mathrm{hr}$, Air & 800.00 & 18.200 & 18.200 & 19.800 \\
\hline PMWY-2, 4th & 1200C/1hr, Air & 800.00 & 20.800 & 20.900 & 19.000 \\
\hline PMWY-2, 1st* & 1200C/1hr, Air & 900.00 & 11.400 & 12.100 & 36.000 \\
\hline PMWY-2, 2nd* & 1200C/1hr, Air & 900.00 & 12.400 & 13.100 & 22.500 \\
\hline PMWY-2, 3rd* & 1200C/1hr, Air & 900.00 & 13.800 & 14.700 & 10.800 \\
\hline PMWY-2, 4th & 1200C/1hr, Air & 900.00 & 13.000 & 13.700 & 17.800 \\
\hline PMWY-2, 1st* & 1200C/1hr, Air & 1000.0 & 11.400 & 11.600 & 13.700 \\
\hline PMWY-2, 2nd* & 1200C/1hr, Air & 1000.0 & 12.400 & 13.600 & 11.500 \\
\hline PMWY-2, 3rd* & $1200 \mathrm{C} / 1 \mathrm{hr}, \mathrm{Air}$ & 1000.0 & 12.100 & 12.200 & 9.2000 \\
\hline PMWY-2, 4th & 1200C/1hr, Air & 1000.0 & 11.400 & 11.900 & 21.200 \\
\hline PMWY-3, 1st & $1200 \mathrm{C} / 1 \mathrm{hr}, \mathrm{Air}$ & 800.00 & 19.600 & 20.900 & 10.000 \\
\hline PMWY-3, 3rd & $1200 \mathrm{C} / 1 \mathrm{hr}, \mathrm{Air}$ & 800.00 & 19.300 & 20.900 & 10.200 \\
\hline PMWY-3, 1st & $1200 \mathrm{C} / 1 \mathrm{hr}, \mathrm{Air}$ & 900.00 & 12.500 & 14.400 & 6.0000 \\
\hline PMWY-3, 3rd & $1200 \mathrm{C} / 1 \mathrm{hr}$, Air & 900.00 & 16.600 & 16.700 & 7.7000 \\
\hline PMWY $-3,1$ st & $1200 \mathrm{C} / 1 \mathrm{hr}_{\text {, Air }}$ & 1000.0 & 9.4000 & 12.800 & 10.200 \\
\hline PMWY-3, 3rd & $1200 \mathrm{C} / 1 \mathrm{hr}$, Air & 1000.0 & 12.200 & 13.200 & 6.1000 \\
\hline
\end{tabular}

*Samples extracted from heat-treated tubes. For the $4^{\text {th }}$ batch, the ASTM samples were reheated at $1200^{\circ} \mathrm{C}-1 \mathrm{hr}$ prior to testing as furnace gradients are assumed to cause point to point variations in the recrystallized microstructure. Modest improvement is noted in PMWY-1 as a result of this re-heat treatment. 
Table 9. High Temperature Transverse Mechanical Properties for the Extruded Tubes

\begin{tabular}{|c|c|c|c|c|}
\hline Sample & Heat Treatment & Test Temp. & YS, Ksi & UTS, Ksi \\
\hline PMWY-1, 3rd & $1200 \mathrm{C} / 1 \mathrm{hr}$, Air & 800.00 & 15.800 & 18.600 \\
\hline PMWV-1, 4th & $1200 \mathrm{C} / 1 \mathrm{hr}, \mathrm{Air}$ & 800.00 & 17.800 & 20.100 \\
\hline PMWY-1,3rd & 1200C/1hr, Air & 900.00 & 10.000 & 11.100 \\
\hline PMWV-1, 4th & $1200 \mathrm{C} / 1 \mathrm{hr}, \mathrm{Air}$ & 900.00 & 10.100 & 11.000 \\
\hline PMW $/-1,3 r d$ & $1200 \mathrm{C} / 1 \mathrm{hr}$, Air & 1000.0 & 11.300 & 11.700 \\
\hline PMWY-1, 4th & $1200 \mathrm{C} / \mathrm{hr}, \mathrm{Air}$ & 1000.0 & 8.0000 & 8.4000 \\
\hline PMWY -2, 3rd & $1200 \mathrm{C} / 1 \mathrm{hr}, \mathrm{Air}$ & 800.00 & 16.200 & 16.300 \\
\hline PMWY-2, 4th & $1200 \mathrm{C} / 1 \mathrm{hr}$, Air & 800.00 & 16.600 & 17.800 \\
\hline PMWY-2, 3rd & 1200C/1hr, Air & 900.00 & 10.600 & 11.100 \\
\hline PMWY-2, 4th & $1200 \mathrm{C} / 1 \mathrm{hr}$, Air & 900.00 & 10.400 & 11.200 \\
\hline PMWY-2, 3rd & 1200C/1hr, Air & 1000.0 & 11.800 & 12.100 \\
\hline PMWY -2, 4th & $1200 \mathrm{C} / 1 \mathrm{hr}$, Air & 1000.0 & $4.1000^{*}$ & $4.3000^{*}$ \\
\hline PMWY-3, 3rd & $1200 \mathrm{C} / 1 \mathrm{hr}, \mathrm{Air}$ & 800.00 & 18.600 & 19.100 \\
\hline PMWY-3, 3rd & 1200C/1hr, Air & 900.00 & 12.400 & 12.800 \\
\hline PMWY-3, 3rd & 200C/1hr, Air & 1000.0 & 11.200 & 11.200 \\
\hline
\end{tabular}

Samples extracted by multiple forging split tube sections at $900^{\circ} \mathrm{C}$. Multiple forging steps were required with the specimen given a 15 minute soaking treatment at $900^{\circ} \mathrm{C}$. All samples given a final anneal of $1 / 2 \mathrm{hr}$ at $900^{\circ} \mathrm{C}$.

The tabulated test data provided in Tables 8 and 9 is graphically illustrated in Figures 25a,b for the longitudinal and transverse orientations, respectively. Note that the fully recrystallized microstructure of PMWY-3 specimens (see Figure 19c) exhibits the best performance for both the longitudinal and the transverse oriented specimens. There are subtle variations in the longitudinal and transverse strength response for the respective powder batches. For example all the three powder batches show some work hardening in the longitudinal orientation absent in the transverse orientations. For PMWY-1 and PMWY-3 the transverse strength closely follows the longitudinal strength (albeit a little inferior) but a 50\% drop is observed for the PMWY-2 samples. This is likely attributed to the point-to-point variations in the recrystallized microstructure that may contain isolated un-recrystallized regions.

The transverse orientation specimens were initially produced by hand forging heat-treated tubes into flat sections. Multiple forging steps were required with intermittent 10 min anneals at $900^{\circ} \mathrm{C}$, followed by a final anneal of $1 / 2$ hour. This procedure has been modified to a single step forging of as-extruded tubes followed by recrystallization. These test are currently in progress.

Looking forward to the next section (Progress: Iteration 5) we note that the creep response is particularly affected by the underlying grain structure. In an effort to improve overall grain growth in PMWY-1 and PMWY-2, ASTM E-8 tensile specimens were given additional thermal treatments $\left(1200^{\circ} \mathrm{C}-1 \mathrm{hr}\right)$ and re-tested (results identified as batch 4 tests in Table 9). With the exception of PMWY-1 tested at $1000^{\circ} \mathrm{C}$, the results are inconclusive. Nonetheless, looking to forward to the next section marginal improvements in creep response are being recorded. 
a)
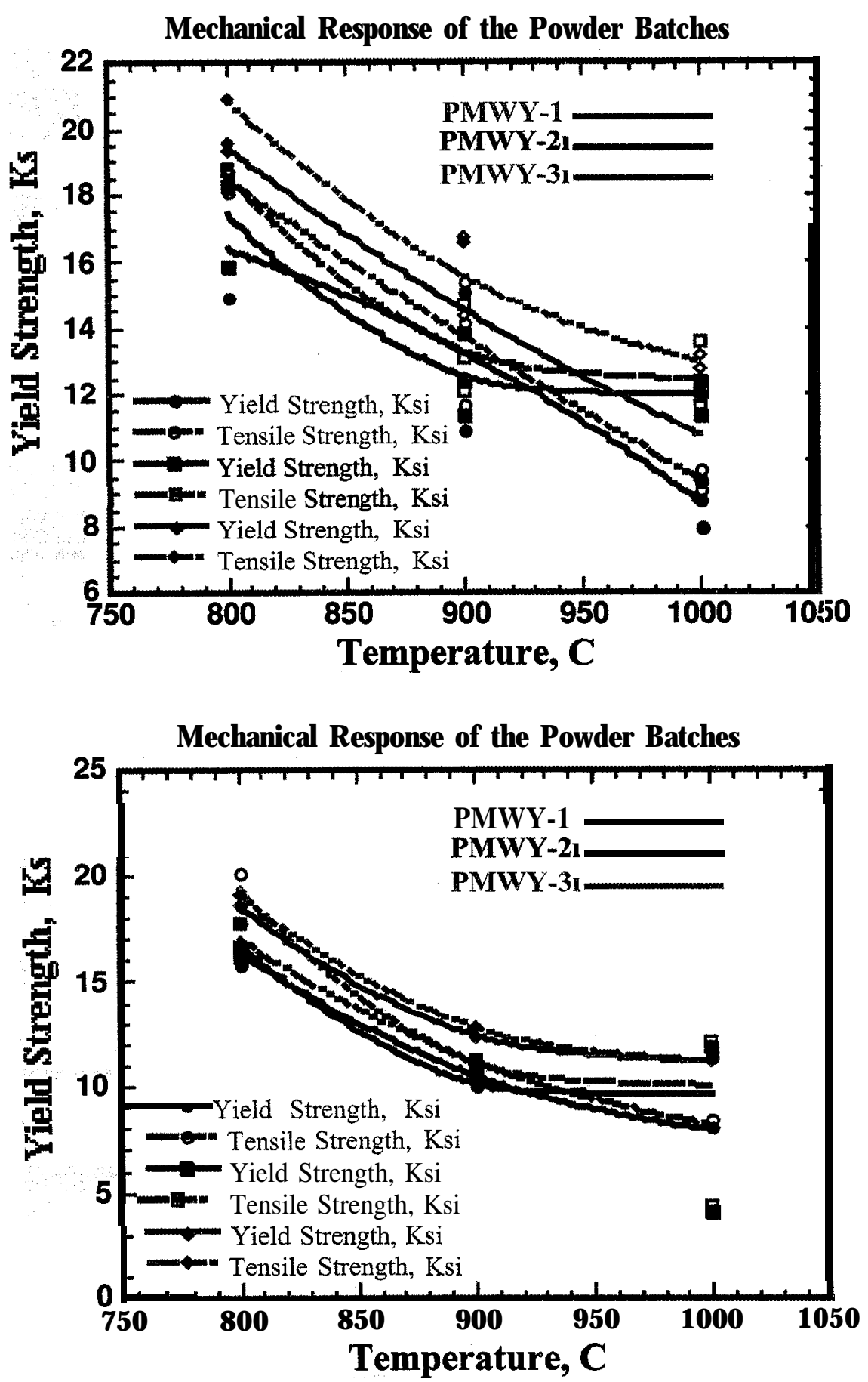

b)

Figure 25. High temperature mechanical response for the a) Longitudinal and b) Transverse orientations. The fully recrystallized microstructure of PMWY-3 (See Figures 18, 19) offers the best response over the entire test-temperature range in either orientation. 


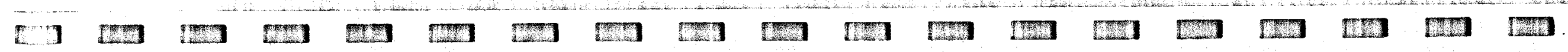
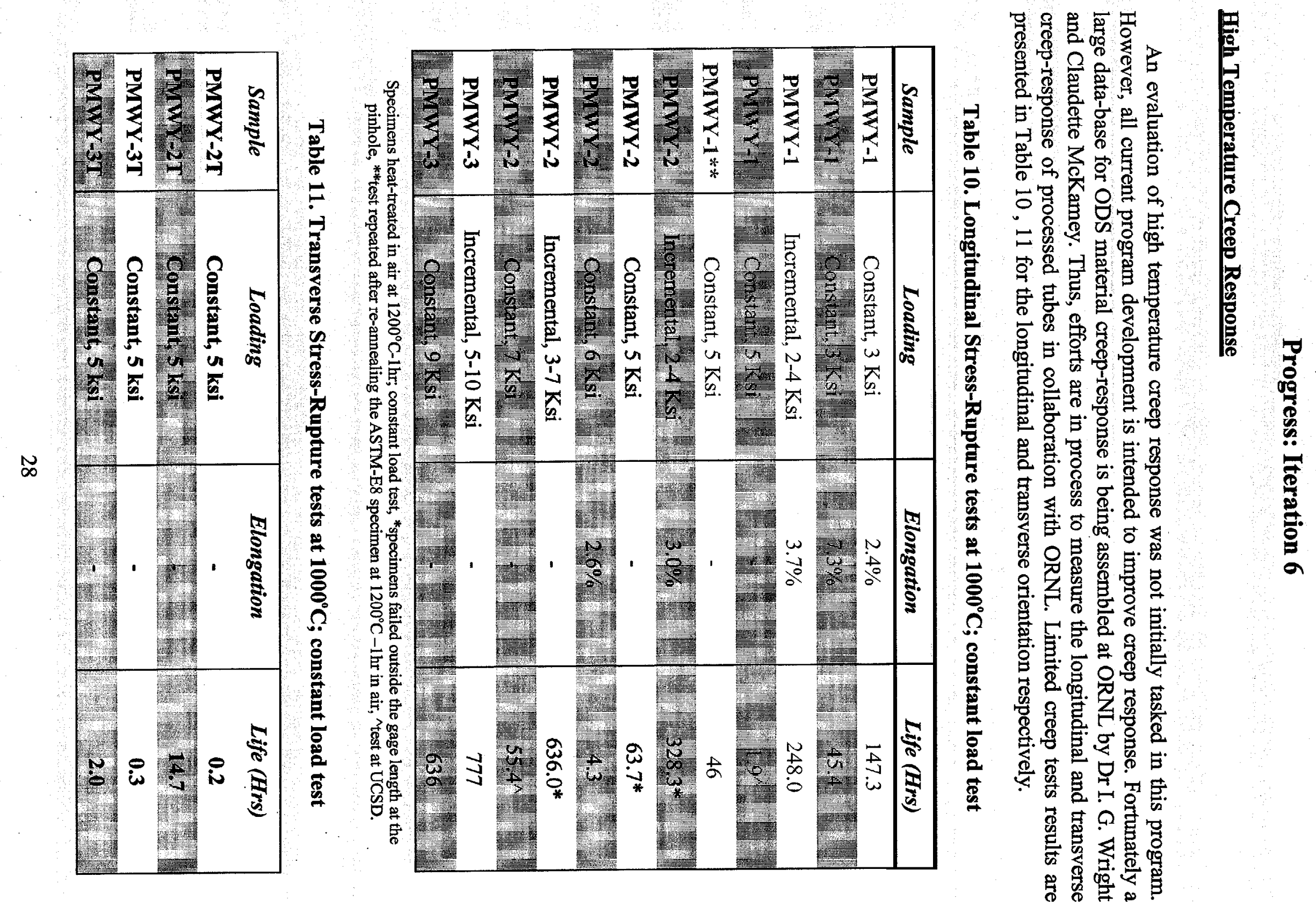

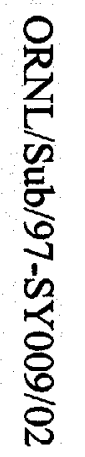



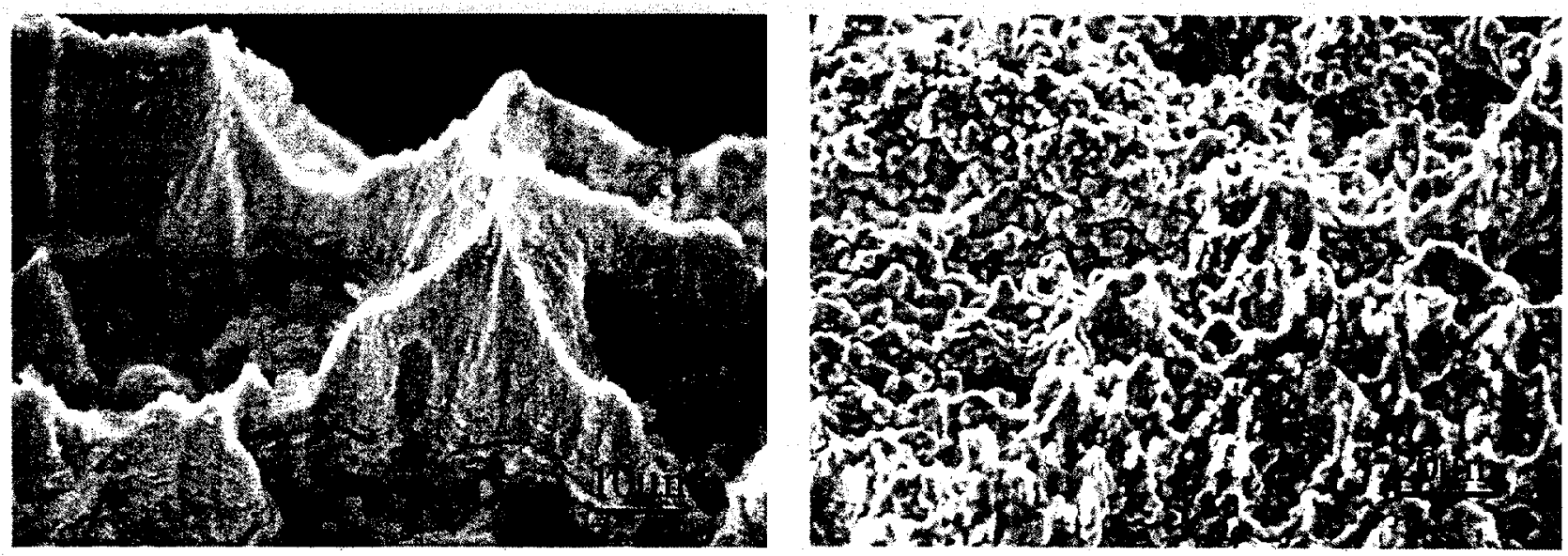

Figure 26. Stress rupture fractures in a) PMWY-1 incrementally loaded at $2-4 \mathrm{Ksi}$ at $1000^{\circ} \mathrm{C}$, life $=248 \mathrm{hrs}$, and b) PMWY-2 loaded at $6 \mathrm{Ksi}$ at $1000^{\circ} \mathrm{C}$, life $=4.3$ hours. Differences in failure substructure are related to the underlying grain structure developed during heat-treatments.

With reference to the Table 10 (longitudinal test results), we note that PMWY-3 exhibits the best performance till date followed by PMWY-2 with PMWY- exhibits the poorest performance. Such differences are directly related to the underlying grain structure developed'in these alloy tubes at the constant heat-treatment temperature of $1200^{\circ} \mathrm{C}-1 \mathrm{hr}$ as indicated in the optical micrographs of Figures 16-1 8 and the transmission electron micrographs of Figure 19. Thus PMWY-1 with the bulk of the un-recrystallized regions across the tube wall exhibits poor creep response. The scatter in PMWY-2 response derives from the exact location in the tube wall where the specimen is spark machined. Since PMWY-2 exhibits incomplete recrystallization, such local factors determine the fraction of fine grain constituent include in the ASTM E-8 specimen gage thickness. Figure 26 illustrates the striking difference in fractures for the fine and coarse-grained materials. Fine g-rained PMWY-1 exhibits high ductile lobes in crept specimens, Figure 26a, whereas no such features are observed in coarse-grained PMWY-2, Figure 26b, or in PMWY-3. Such fracture features therefore offer subtle clues to the underlying grain structure.

ASTM E-8 specimens of PMWY-1 and PMWY-2 were re-heat treated at $1200^{\circ} \mathrm{C}-1 \mathrm{hr}$ to promote grain coarsening. Initial test on a PMWY-1 specimen (labeled ** in Table 10) exhibits the best response recorded till date. Further tests are planned to explore this promising trend.

\section{Creep Deformation R esponse M icrostructures}

Deformation substructures have been examined for high temperature tensile tests and creep tests particularly in fully recrystallized rods and tubes. Deformation microstructures, observed in tensile tests are essentially glide dominated, with $<111>$ dislocations gliding on $\{110\}$ planes. However, the deformation sub-structure under creep conditions evolves with specific conditions of temperature and stress. Two specific cases are illustrated here.

\section{i) Low Temperature-High Stress}

Figure 27 shows deformation substructure in a region immediately below the fracture surface for a PMWY-2 rod specimen creep tested at $900^{\circ} \mathrm{C}$ at $7 \mathrm{Ksi}$. At this temperature, the 
deformation, at least close to the fracture region is comprised of glide d\&locations confined to their respective slip planes. For a nominal stress-rupture testing axis of [111], as is the case for fully recrystallized specimens along the extrusion axis, the operating slip planes are found to be (110), Figure 27b, and (011), Figure 26c, with Burgers vectors $\mathbf{b}=111$ and 111, respectively. Both slip planes and glide dislocations are visible in Figure 26a.

A single dislocation loop (in the center of the micrograph) exhibits cross-slip/climb behavior suggesting that some climb processes are operative even under what may be a fast fracture process. This combination of glide and climb processes is consistent with the DBTT and the prior observation in the fracture morphology changes in tests conducted above $800^{\circ} \mathrm{C}$.
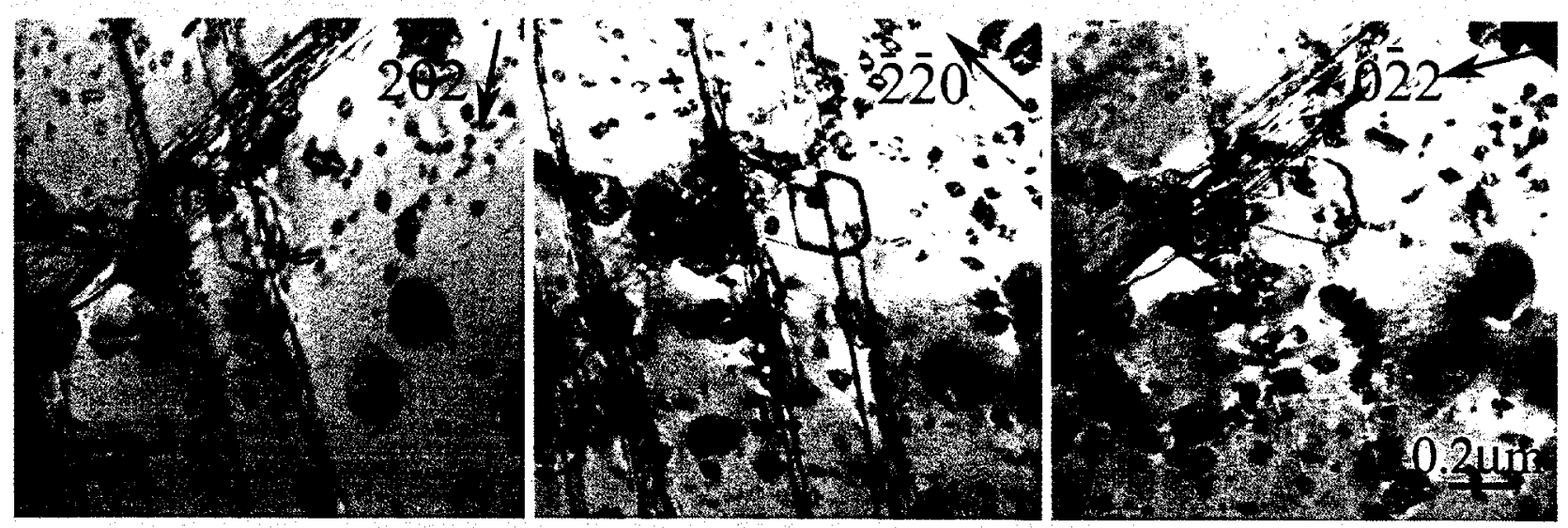

Figure 27. Deformation substructure in creep tested $\left(900^{\circ} \mathrm{C}-7 \mathrm{Ksi}\right)$ PMWY-2 rod specimens.

\section{ii) High Temperature-Low Stress}

Figure 28 shows deformation substructure in a region immediately below the fracture surface for a PMWY-2 rod specimen creep tested at $1000^{\circ} \mathrm{C}$ at $5 \mathrm{Ksi}$. The deformation substructure is no longer dominated by glide - and no dominant slip plane activity is observed. The $<111>$ type dislocations are pinned by fine $\mathrm{Y}_{2} \mathrm{O}_{3}\left(\right.$ or $\left.\mathrm{Y}_{2} \mathrm{O}_{3} \cdot \mathrm{Al}_{2} \mathrm{O}_{2}\right)$ precipitates, and in the process of climb. The dislocations exhibit a characteristic $\mathrm{g} \cdot \mathrm{b}=\mathrm{O}$ or $\mathbf{g} \cdot \mathbf{b x u}=\mathbf{0}$ type of invisibility contrast for $\mathbf{g}=\mathbf{0 2 2}$, Figure $27 \mathrm{c}$, and $\mathbf{g}=\mathbf{2 0 2}$, Figure $27 \mathrm{~d}$, yielding a Burgers vector $b=1 \overline{1}$. Furthermore, the dislocation edge segments cannot be reconciled to likely slip planes. The deformation at this stage is therefore dominated by diffusion controlled climb events.

Two features of the microstructure are of additional interest. In the bi-modal precipitate distribution of Figure 29a one set of precipitates (at the prior grain/particle boundaries) shows significant strain contrast under 2-beam imaging conditions. This particular precipitate appears to trap some dislocations presumably as an energetic process of lowering its strain energy. Figure $29 \mathrm{~b}$ shows that fine particles (typically $10-20 \mathrm{~nm}$ ) are particularly suited for dislocation pinning in the climb regime. These particles then are the yttrium oxides (or $\mathrm{Y}_{2} \mathrm{O}_{3} \cdot \mathrm{Al}_{2} \mathrm{O}_{2}$ ) and not the impurity oxides or nitrides of aluminum (as identified by quantitative EDS). 


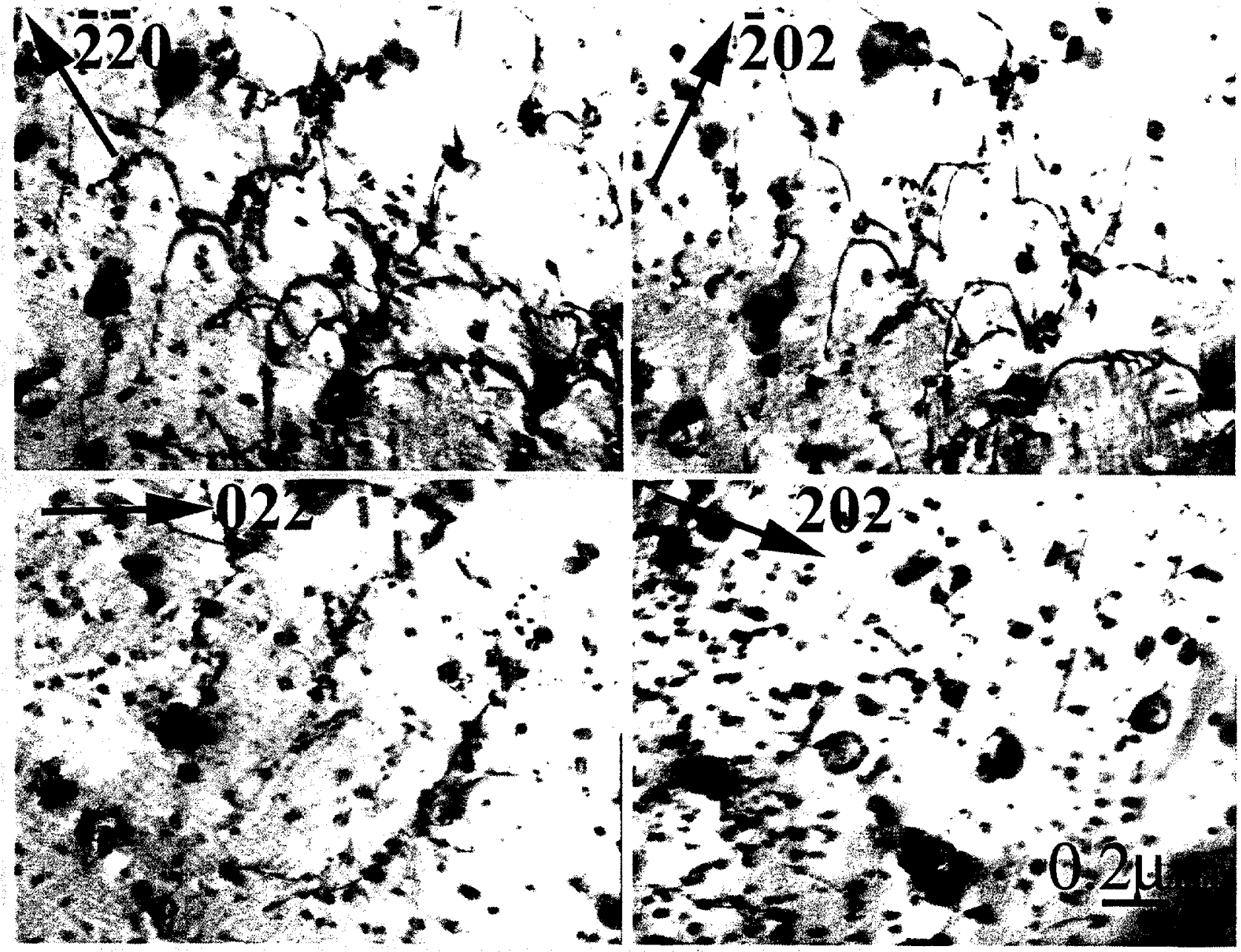

Figure 28. Deformation substructure in creep tested $\left(1000^{\circ} \mathrm{C}-5 \mathrm{Ksi}\right)$ PMWY-2 rod specimens.
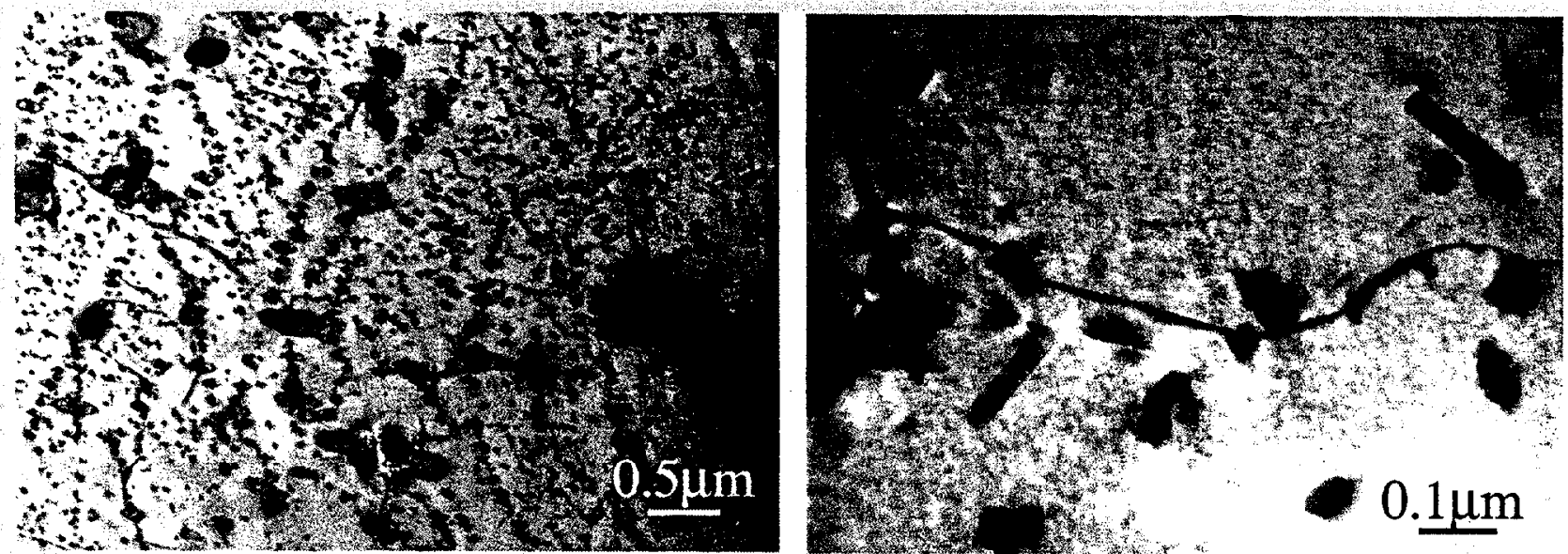

Figure 29. Deformation substructures in crept PMWY-2 specimens. A) Tested at $1000^{\circ} \mathrm{C}$ at $5 \mathrm{~K}$ si. Note strain contrast around selected precipitates that trap dislocations. b) Tested at $1050^{\circ} \mathrm{C}$ at 3-6Ksi where fine $\mathrm{Y}_{2} \mathrm{O}_{3}$ precipitates offer the best dislocation pinning response. 


\section{Summary and Conclusions}

The oxide dispersion strengthened (ODS) Fe 3 Al-based alloy powders (PMWY-1, PMWY-2, PMWY-3) were successfully consolidated into solid rods and tubes by the single step hot extrusion methodologies. The creep performance ODS- $\mathrm{Fe}_{3} \mathrm{Al}$ materials has been initially studied in Longitudinal and to a limited extent in the Transverse orientations, and deemed acceptable within the prescribed performance envelope. It is interesting to note that grain growth kinetics are affected by interstitial impurity content, which limit the extent of recrystallized regions observed in the tube wall. Consequently, the microstructures exhibiting the best creep response (i.e., PMWY-3) are ones that undergo complete recrystallization. Such creep performance will continue to be evaluated specifically for the tube specimens in the next phase of the research program. The following conclusions are possible based on our studies till date:

1. The ODS- $\mathrm{Fe}_{3} \mathrm{Al}$ rods and tubes can be fully consolidated at $1000^{\circ} \mathrm{C}$ and at extrusion ratios of about 16: 1, while exhibiting reasonable post-extrusion recrystallization kinetics.

2. Recrystallization is initiated in all powder batches heat-treated at $1200^{\circ} \mathrm{C}-1 \mathrm{hr}$ with recrystallized grain sizes of the order of $200-5000 \mu \mathrm{m}$. However the growth kinetics are affected by the overall interstitial impurity content, such only partial wall section of the tube undergoes large-scale grain growth.

3. Secondary grain growth kinetics exhibit an direct relationship with the total interstitial impurity content of the milled powder batches, with the purest batch PMWY-3 exhibiting the most favorable grain growth.

4. Creep response if the respective powder batches is proportional to the underlying grain structure produced via heat-treatments. Thus powder batch PMWY-3 with the complete recrystallized section offers the best creep response.

5. Powder batch milling appears to be the single most pervasive processing component dominates microstructural and material response. It is suggested that coarse nitrides and oxides of aluminum (formed during milling) while inhibiting recrystallization grain growth (as observed in PMWY-2 and PMWY-3) are ineffective in dislocation pinning in the climb regime. Effective pinning is only provided by the fine $\mathrm{Y}_{2} \mathrm{O}_{3}$ and $\mathrm{Y}_{2} \mathrm{O}_{3} \cdot \mathrm{Al}_{2} \mathrm{O}_{3}$ precipitates.

6. Preliminary efforts to enhance the growth kinetics in PMWY-1 and PMWY-2 primarily by prolonging the hold time at $1200^{\circ} \mathrm{C}$ improve the ensuing creep response incrementally.

\section{Acknowledgements}

The support and guidance of Dr. I.G. Wright and Dr. V.K. Sikka is gratefully acknowledged. 


\section{References}

1. V.K. Sikka, S. Vishwanathan, C.G. McKamey, 1993, Structural Intermetallics, (TMS) 483

2. P.G. Sanders, V.K. Sikka, C.R. Howell, R.H. Baldwin, 1991, Scripta Met., 25, 2365.

3. I.G. Wright, B.A. Pint, E.K. Ohriner and P.F. Tortorelli, 1996, Proc. I I th Ann. Conf. on Fossil Energy Materials, ORNL Report ORNL/FMP-96/1, CONF-9605 167, p. 359

4. V.K. Sikka, I.G. Wright and B.K. Kad, Proc. 12th Ann. Conf. Fossil Energy Materials, Knoxville, TN, May 1998.

5. B.K. Kad, S.E. Schoenfeld, R.J. Asaro, C.G. McKamey, V.K. Sikka, 1997, Acta Metall., 45, No.4,p. 1333.

6. B.K. Kad, V.K. Sikka and I.G. Wright, 13th Ann. Conf. Fossil Energy Materials, Knoxville, TN, May 1999

7. B.K. Kad, R.N. Wright, I.G. Wright and V.K. Sikka, 14th Ann. Conf. Fossil Energy Materials, Knoxville TN, May 2000. 


\section{APPENDIX}

(New Alloys Distribution List) 


\section{ALLISON GAS TURBINE DIVISION}

P.O. Box 420

Indianapolis, IN 46206-0420

P. Khandelwal (Speed Code W-5)

R. A. Wenglarz (Speed Code W-1 6)

BABCOCK \& WILCOX

Domestic Fossil Operations

20 South Van Buren Avenue

Barberton, $\mathrm{OH} 44023$

M. Gold

CANADA CENTER FOR MINERAL \& ENERGY

TECHNOLOGY

568 Booth Street

Ottawa, Ontario

Canada K1A OG1

R. Winston Revie

Mahi Sahoo

COLORADO SCHOOL OF MINES

Department of Metallurgical Engineering

Golden, CO 80401

G. R. Edwards

DOE

DOE OAK RIDGE OPERATIONS

P. 0. Box 2008

Building 4500N, MS 6269

Oak Ridge, TN 37831

M. H. Rawlins

DOE

National Energy Technology Laboratory

3610 Collins Ferry Road

P.O. Box 880

Morgantown, WV 26507-0880

D. C. Cicero

F. W. Crouse, Jr.

R. A. Dennis

N. T. Holcombe

W. J. Huber

T. J. McMahon

J. E. Notestein
DOE

National Energy Technology Laboratory

626 Cochrans Mill Road

P.O. Box 10940

Pittsburgh, PA 15236-0940
A. L. Baldwin
G. V. McGurl
U. Rao
L. A. Ruth
T. M. Torkos

DOE

OFFICE OF FOSSIL ENERGY

FE-72

19901 Germantown Road

Germantown MD 20874- 1290

F. M. Glaser

DOE

OFFICE OF BASIC ENERGY SCIENCES

Materials Sciences Division

ER-131 GTN

Washington, DC 20545

H. M. Kerch

FOSTER WHEELER DEVELOPMENT CORPORATION

Materials Technology Department

John Blizard Research Center

12 Peach Tree Hill Road

Livingston, NJ 07039

J. L. Blough

IDAHO NATIONAL ENGINEERING

LABORATORY

P.O. Box 1625

Idaho Falls, ID 83415

R. N. Wright 
LEHIGH UNIVERSITY

Materials Science \& Engineering

Whitaker Laboratory

5 E. Packer Avenue

Bethlehem, PA 18015

J. N. DuPont

OAK RIDGE NATIONAL LABORATORY

P.O. Box 2008

Oak Ridge, TN 37831

M. P. Brady

P. T. Carlson

J. M. Crigger (2 copies)

R. R. Judkins

C. T. Liu

J. H. Schneibel

R. W. Swindeman

P. F. Tortorelli

I. G. Wright

PACIFIC NORTHWEST LABORATORY

P. 0. Box 999, K3-59

Battelle Boulevard

Richland, WA 99352

R. N. Johnson

THE UNIVERSITY OF LIVERPOOL

Liverpool, United Kingdom

L69 3BX

A. R. Jones

THE WELDING INSTITUTE

Abington Hall, Abington

Cambridge CB1 6AL

United Kingdom

P. L. Threadgill

\section{UNIVERSITY OF CALIFORNIA}

AT SAN DIEGO

Department of Applied Mechanics and Engineering

Sciences

La Jolla, CA 92093-0411

B. K. Kad
UNIVERSITY OF TENNESSEE AT

KNOXVILLE

Materials Science and Engineering

Department

Knoxville, TN 37996

P. K. Liaw

WEST VIRGINIA UNIVERSITY

Department of Physics

Morgantown, WV 26506-63 15

B. R. Cooper 